\title{
Analysis of operational issues in hydrothermal liquefaction and supercritical water gasification processes: a review
}

\author{
Niloufar Ghavami ${ }^{1}$ Karhan Özdenkçi ${ }^{1}$ - Gabriel Salierno ${ }^{1}$. Margareta Björklund-Sänkiaho ${ }^{1}$. Cataldo De Blasio ${ }^{1}$
}

Received: 12 August 2021 / Revised: 24 November 2021 / Accepted: 30 November 2021

(c) The Author(s) 2021

\begin{abstract}
Biomass is often referred to as a carbon-neutral energy source, and it has a role in reducing fossil fuel depletion. In addition, biomass can be converted efficiently into various forms of biofuels. The biomass conversion processes involve several thermochemical, biochemical, and hydrothermal methods for biomass treatment integration. The most common conversion routes to produce biofuels include pyrolysis and gasification processes. On the other hand, supercritical water gasification (SCWG) and hydrothermal liquefaction (HTL) are best suitable for converting biomass and waste with high moisture content. Despite promising efficiencies, SCWG and HTL processes introduce operational issues as obstacles to the industrialization of these technologies. The issues include process safety aspects due to operation conditions, plugging due to solid deposition, corrosion, pumpability of feedstock, catalyst sintering and deactivation, and high production costs. The methods to address these issues include various reactor configurations to avoid plugging and optimizing process conditions to minimize other issues. However, there are only a few studies investigating the operational issues as the main scope, and reviews are seldomly available in this regard. Therefore, further research is required to address operational problems. This study reviews the main operational problems in SCWG and HTL. The objective of this study is to enhance the industrialization of these processes by investigating the operational issues and the potential solutions, i.e., contributing to the elimination of the obstacles. A comprehensive study on the operational issues provides a holistic overview of the biomass conversion technologies and biorefinery concepts to promote the industrialization of SCWG and HTL.
\end{abstract}

Keywords Biofuels $\cdot$ Biomass conversion $\cdot$ Supercritical water gasification $\cdot$ Hydrothermal liquefaction $\cdot$ Operational risks

$\begin{array}{ll}\text { Abbreviations } \\ \text { BTU } & \text { British Thermal Unit } \\ \text { EU } & \text { European Union } \\ \text { HTL } & \text { Hydrothermal liquefaction } \\ \text { PTG } & \text { Power to gas } \\ \text { CaL } & \text { Calcium looping cycle } \\ \text { SCWG } & \text { Supercritical water gasification } \\ \text { CSTR } & \text { Continuous stirred-tank reactor } \\ \text { SCWO } & \text { Supercritical water oxidation } \\ \text { LCA } & \text { Life cycle assessment } \\ \text { AP } & \text { Aqueous phase } \\ \text { SCW } & \text { Supercritical water } \\ \text { WBL } & \text { Weak black liquor } \\ \text { WGS } & \text { Water gas shift }\end{array}$

Niloufar Ghavami

niloufar.ghavami@abo.fi

1 Faculty of Science and Engineering, Laboratory of Energy Technology, Åbo Akademi University, Rantakatu 2, 65100 Vaasa, Finland

$\begin{array}{ll}\text { Adt } & \text { Air-dried ton } \\ \text { SCWR } & \text { Supercritical water reforming } \\ \text { ASCWR } & \text { Autothermal supercritical water reforming } \\ \text { GC } & \text { Gas chromatographs } \\ \text { WG } & \text { Wet gas meter } \\ \text { TWR } & \text { Transpiring-wall reactor } \\ \text { HHV } & \text { High heating value } \\ \text { SCPW } & \text { Supercritical pressurized water } \\ \text { EWBB } & \text { Extracted white birch bark } \\ \text { SCFs } & \text { Supercritical fluids } \\ \text { HTL-WW } & \text { High strength hydrothermal liquefaction } \\ & \text { wastewater } \\ \text { PWO } & \text { Partial wet oxidation }\end{array}$

\section{Introduction}

Increasing energy demand due to the world population growth and rising prosperity represents a real challenge in current times. According to the energy perspective report 
[1], the global energy demand will be 675 quadrillion BTUs in 2040, increasing about $20 \%$ compared to 2017 levels. However, as the main source of energy, fossil fuel usage causes environmental problems associated with carbon emissions and other pollutants as well as fossil sources being depleted. Consequently, there is an urgent demand to eliminate the usage of fossil sources. Replacing fossil fuels with renewable resources reduces environmental effects due to greenhouse gas emissions [2]. Renewable energy consumption has increased more than $10 \%$ annually in the European Union (EU) countries, approximately one-fourth of the global renewable energy consumption. Most of the EU countries are setting goals to enhance renewable energy production [3]. By 2050, the EU intends to be climate-neutral and emit net-zero greenhouse gases. For instance, Finland is among the leading countries increasing solid biomass and bio-waste use for energy production an average of 3.6\% yearly since 2010 [4, 5]. According to Sikkema et al. [4], Baltic countries surpassed their solid biomass energy share goals.

Biomass is an abundant and renewable source, thus introducing the promising potential for replacing fossil sources. Therefore, its use would contribute to the carbon neutrality of the energy sector, arising as an increasingly plausible alternative to fossil fuels [6-9]. However, there is a debate regarding sustainability and carbon-neutrality characteristics when converting 1st-generation biomass, i.e., edible biomass compromising with the food and animal feed. Processing 1st-generation biomass might cause carbon emissions equal to or even more than fossil-based production when the plant growth steps are also considered [10], despite relatively simple processes and close-to-uniform feedstock $[11,12]$. Therefore, it is the 2nd-generation biomass having the potential for the complete replacement of fossil fuels, i.e., non-edible biomass and waste/by-products of existing biomass sectors. Some examples of 2nd-generation biomass include wood residues from sawmills, agricultural residues, dedicated non-edible crops, municipal sewage sludge, black liquor in the pulp mills, food waste, manure, and algae. However, traditional waste management methods such as incineration, dumping, landfilling, and composting result in environmental pollution [13-15]. In other words, managing large amounts of bio-waste and waste-to-energy conversion technologies are challenging issues in the following years. Bio-waste is generated significantly and has a high potential for biofuel production. On the other hand, valorization of 2nd-generation biomass requires advanced processes due to feedstock variety.

The 2nd-generation biomass conversion is classified as thermal, biological, and hydrothermal processes [16, 17]. The biological conversion involves enzymes or organisms converting biomass into biofuels, such as saccharification (hydrolysis of food constituents, cellulose, and hemicellulose into sugars) followed by fermentation to produce alcohols [18]. The biological conversion processes can selectively produce the desired product rather than generating numerous intermediate compounds as in thermochemical conversions. However, the biological conversion is suitable only for food waste, manure, sewage sludge, and food-related (e.g., food waste and side streams of food production plants) or digestion-related wastes (e.g., sewage sludge and manure). In contrast, processing lignocellulosic biomass is usually inefficient due to inhibiting impacts of lignin, thus requiring prior fractionation. On the other hand, perfect fractionation of 2nd-generation biomass might be unfeasible [19]. As for drawbacks from the flexibility and adaptability viewpoints, these processes require very long residence time (hours to days) and introduce issues of cell culture recovery and difficult process control. The thermal conversion methods include combustion [20], gasification [21-24], and pyrolysis [25-28]. However, burning biomass can also create pollution whereas new conversion technologies including biochemical and thermochemical methods reduce the environmental impacts [29]. For instance, comparing gasification and combustion for electricity production from forest biomass, gasification was stated to provide higher energy efficiency and cleaner gas outlet regarding $\mathrm{NO}_{\mathrm{x}}$ and $\mathrm{SO}_{\mathrm{x}}$ content [30]. In addition, the $\mathrm{CO}_{2}$ produced by biomass thermochemical conversion could be integrated within power-to-gas (P2G) technologies and processed with chemical looping to produce methane $[31,32]$. The gasification and pyrolysis products are further processed to produce various biofuels and chemicals $[26,33]$. On other hand, the thermal processes require drying as an energy-consuming pre-treatment when processing biomass due to high moisture content. For instance, as stated by an exergy analysis of biofuels, the evaporation step is the main source of exergy loss in thermal processes, and hydrothermal processes provide higher exergy efficiency [34]. Instead, the hydrothermal processes use water as the reaction medium and avoid the evaporation or drying steps, thus providing higher energy efficiency when processing biomass [35].

The main hydrothermal processes include supercritical water gasification (SCWG) and hydrothermal liquefaction (HTL), producing syngas and bio-oil respectively. These processes are more energy-efficient than the thermal processes producing the same products, i.e., pyrolysis and thermal gasification, for biomass. The pyrolysis and gasification reactors are suitable for biomass feedstock with $10 \%$ water content, otherwise requiring drying as the pre-treatment $[15$, 36]. SCWG becomes more efficient than the gasification process (including the drying step) for feedstock having $30 \%$ or more moisture [37]. For instance, as an alternative treatment for black liquor to the recovery boiler treatment, gasification has the same issue of drying need despite the improvements in efficiency relative to the recovery boiler while SCWG is 
more efficient than gasification as well [38-40]. In addition, HTL oil has less oxygen content than pyrolysis oil, thus requiring less hydrogen when upgrading [41].

The industrial implementation of SCWG and HTL would enable enhanced supply chains of biomass processing through the effective valorization of waste and side streams [42]. However, the industrialization of SCWG and HTL technologies is still a challenge due to operational issues. Some operational problems include plugging, corrosion, catalyst deactivation, and high production costs as the obstacles to the industrialization of these processes. In addition, other operational constraints include process safety regarding high pressure and temperature and pumpability of the feedstock. On the other hand, despite many studies investigating the product yields and/or economic performances with respect to process conditions, the obstacles are discussed briefly as additional aspects. There are only a few studies investigating the operational issues as the main scope. Therefore, further research is required to address the operational obstacles for the industrialization of SCWG and HTL processes.

The objective of this study is to investigate the operational issues and the potential solutions comprehensively, i.e., contributing to the definition and elimination of the obstacles for the industrialization of SCWG and HTL processes. After summarizing the current state-of-art in these processes, this study reviews the operational issues together with associated root causes and potential solutions for each issue. A comprehensive study on the operational issues provides a holistic overview of the biomass conversion technologies and biorefinery concepts to promote the industrialization of SCWG and HTL. In addition, this study also discusses the future aspects of further investigations on the operational issues, process integration, and biorefinery concepts. Research on constraints due to operational issues provides a framework for integrating these processes into biorefineries and for evaluating the economic and environmental performances.

\section{Current state-of-art in SCWG and HTL processes}

The physical properties of water play a crucial role in hydrothermal processes as water is the reaction medium $[43,44]$. The state of water is pointed as sub-critical and supercritical regions from the hydrothermal conversion viewpoint: a critical point of $374{ }^{\circ} \mathrm{C}$ and $22.1 \mathrm{MPa}$. There are essential changes in the properties of water with temperature and pressure in both regions $[44,45]$. The viscosity decreases with temperature. The density decreases gradually with the temperature at the sub-critical region and very sharply around the critical point while decreasing very slightly at the supercritical region. The dielectric constant also decreases with the temperature at the sub-critical region while decreasing sharply around critical temperature and remaining almost constant with the temperature at the supercritical region [44]. In addition, the stability and number of hydrogen bonds decrease with temperature as well [44]. Consequently, the solvent behavior of water becomes like a non-polar organic solvent at the supercritical region, despite individual water molecules still being polar [44]. In other words, water becomes an effective solvent for organics and gases at the supercritical region while the solubility of inorganic salts drops to parts per million scales. In contrast, the dissociation constant (or ionic product) increases with temperature at the sub-critical region from $10^{-14}$ at $25^{\circ} \mathrm{C}$ to around $10^{-11}$ at close to critical temperature under a pressure of 250 bars [46]. However, the dissociation constant decreases very sharply with temperature around the critical point and slightly at the supercritical region, e.g., down to lower than $10^{-24}$ at $600{ }^{\circ} \mathrm{C}[46]$.

Water properties and operating conditions influence the product distribution and reaction mechanism. At HTL conditions $\left(300-350{ }^{\circ} \mathrm{C}, 40-250\right.$ bars, and residence time of 15-60 min), biomass decomposition results in 30-40\% bio-oil yield (dry basis by weight) as the main product while generating oxygenated organics in aqueous phase and char as the by-products. Meanwhile, in SCWG conditions (500-700 ${ }^{\circ} \mathrm{C}, 250$ bars, and $1-5 \mathrm{~min}$ ), biomass is decomposed further into gases, thus syngas being the main product. Char is a major by-product of SCWG, and the aqueous phase includes oxygenated organics in minor amounts. The biomass decomposition occurs through an ionic mechanism under HTL conditions because of the high ionic product of water. This provides an ideal condition for acid- or basecatalyzed reactions. In contrast, the SCWG conditions lead to radical mechanisms and faster decomposition due to the very low ionic product of water and higher temperature. Water acts as a reagent, solvent, and source of free radicals and hydrogen during this process $[43,47]$.

The hydrothermal decomposition of biomass occurs in five main steps: hydrolysis/depolymerization of polymeric substances, decomposition of monomers into intermediate compounds, gasification of those intermediates, equilibrium reactions among gases, and the reactions of char and salts. For instance, the depolymerization of lignocellulosic biomass results in phenolic compounds as lignin fragments and sugars as monomers of cellulose and hemicellulose. Hydrolysis of starch also results in glucose. In addition, glucose forms fructose through isomerization reaction [48, 49]. After the depolymerization step, the monomers generate lighter compounds such as carboxylic acids, furans, aldehydes, phenols, and alcohols through decomposition or dealkylation reactions. Then, the gases are formed through reforming reactions including steam reforming and decarboxylation. The main equilibrium reactions are methanation and water-gas-shift (WGS) reactions among the gases. The 
reactions of solid substances include char gasification and repolymerization of phenolics $[50,51]$. The repolymerization reactions generate mainly char at SCWG conditions whereas bio-oil is the main product of repolymerization at the temperature of HTL [52]. The overall decomposition schemes were illustrated for lignin [50] and cellulose [53], including both hydrothermal and thermal decomposition routes, and the main reactions were also illustrated in detail [54]. The product distribution is determined by the process conditions including temperature, residence time, catalyst, reactor material, biomass constituents, and biomass concentration at the reactor inlet. Meanwhile, pressure does not have a major impact on the product yields $[55,56]$.

Temperature is the main condition influencing the reaction kinetics, thus determining the product yields and quality. The bio-oil yield increases with temperature, at temperatures below $300{ }^{\circ} \mathrm{C}$ since the biomass decomposition is slow and/or incomplete [52]. However, high temperatures around $400{ }^{\circ} \mathrm{C}$ cause decomposition of bio-oil, and higher temperatures cause the formation of char through repolymerization instead of oil $[52,57]$. Consequently, the temperature range of HTL is $300-350{ }^{\circ} \mathrm{C}$, high temperature in the sub-critical region, as observed in HTL studies with various feedstocks [52, 57-59]. The gasification efficiency and total gas yields also increase with temperature in SCWG processes while the individual gas yields depend also on the other conditions and biomass type. For instance, temperature promotes the yields of hydrogen, methane, and carbon dioxide while carbon monoxide yield decreases with temperature, as experimented with sucrose and isoeugenol in stainless steel reactor at $500-700{ }^{\circ} \mathrm{C}$ [40]. Temperature also determines the rate-limiting step of biomass conversion. The hydrolysis rate becomes much faster than the further decomposition of monomers at supercritical water conditions while the hydrolysis step is slower and rate-limiting step at sub-critical water conditions $[49,60]$.

Catalyst is another important parameter influencing the product yields by promoting various decomposition steps: improving the yields and enabling lower temperatures for feasible operations. The main catalyst types include alkali metals, transition metals, activated carbon, and metal oxides as conventional catalysts used for SCWG and HTL processes [61-63]. Activated carbon is an effective catalyst for water-gas shift and methanation reactions [47]. Alkali metals promote the ionic reactions and hydrolysis step at the HTL conditions while promoting the gasification and WGS reactions at SCWG conditions [47, 64]. For instance, WGS reaction may not reach equilibrium in SCWG processes in the absence of alkali metals, thus gas products containing a significant amount of carbon monoxide, while alkali metals promote WGS reaction towards hydrogen and carbon dioxide formation at high temperature when there is excess water [40]. The alkali salts have influence on hydrogen yields as $\mathrm{NaOH}>\mathrm{KOH}>\mathrm{Ca}(\mathrm{OH})_{2}>\mathrm{K}_{2} \mathrm{CO}_{3}>\mathrm{Na}_{2} \mathrm{CO}_{3}>\mathrm{NaHCO}_{3}$ [65]. These alkali salts are used in HTL processes as well as $\mathrm{LiOH}, \mathrm{CsOH}$, and $\mathrm{RbOH}$ [66]. For instance, the presence of $\mathrm{KOH}$ increased bio-oil yield by around $40 \%$ (by weight) while the yield was $18 \%$ without catalyst in HTL of birch sawdust [63]. The solid residue was also decreased from 33 to $12 \%$ in the presence of $\mathrm{KOH}$ catalyst [63]. In addition, alkali metals inhibit char and tar formation as well by inhibiting the easily-polymerizing unsaturated compounds [64]. Transition metals promote also the gasification reactions and are active at lower temperatures as well, thus enabling catalytic SCWG process at $400-500{ }^{\circ} \mathrm{C}[67,68]$. Transition metals can also improve hydrogen selectivity and conversion rate as well as catalyze methanation and steam reforming reactions [47]. Among the transition metals, nickel has a low cost while ruthenium has higher activity and stability [47]. In addition, the reactor wall also has a catalytic impact on biomass decomposition. For instance, the Inconel reactor promotes gasification reactions at high temperatures $\left(600{ }^{\circ} \mathrm{C}\right.$ or above) more than stainless steel in the case of SCWG of black liquor [40] while stainless steel is more catalytic than Inconel at $500{ }^{\circ} \mathrm{C}$ [69]. Similarly, the yields are influenced by the surface-to-volume ratio of the Inconel reactor: higher surface area with a constant volume resulting in higher yields [70]. Table 1 shows some heterogeneous catalysts used in SCWG processes together with catalyst properties and hydrogen yields.
Table 1 Heterogeneous catalysts in the SCWG process $[71,72]$

\begin{tabular}{|c|c|c|c|c|}
\hline Catalyst & $\begin{array}{l}\text { Catalyst size } \\
(\mu \mathrm{m} / \mathrm{nm})\end{array}$ & $\begin{array}{l}\text { BET surface area } \\
\left(\mathrm{m}^{2} / \mathrm{g}\right)\end{array}$ & $\begin{array}{l}\text { Total pore volume } \\
(\mathrm{mL} / \mathrm{g})\end{array}$ & Hydrogen yield \\
\hline $\mathrm{Ni} / \mathrm{TiO}_{2}$ & $8.3 \mathrm{~nm}$ & 32 & 0.1 & $0.7 \mathrm{~mol} \mathrm{H}_{2} / \mathrm{mol} \mathrm{C}$ reacted \\
\hline $\mathrm{Ni} / \mathrm{ZrO}_{2}$ & $9.6 \mathrm{~nm}$ & 43 & 0.2 & $1 \mathrm{~mol} \mathrm{H}_{2} / \mathrm{mol} \mathrm{C}$ reacted \\
\hline $\mathrm{Ru} / \mathrm{TiO}_{2}$ & $8.4 \mathrm{~nm}$ & 37 & 0.2 & $0.8 \mathrm{~mol} \mathrm{H}_{2} / \mathrm{mol} \mathrm{C}$ reacted \\
\hline $\mathrm{Ru} / \mathrm{ZrO}_{2}$ & $9.8 \mathrm{~nm}$ & 51 & 0.3 & $0 \mathrm{~mol} \mathrm{H}_{2} / \mathrm{mol} \mathrm{C}$ reacted \\
\hline $\mathrm{Ni} / \alpha-\mathrm{Al}_{2} \mathrm{O}_{3}$ & $118 \mu \mathrm{m}$ & 8 & - & $46 \mathrm{~mol} \mathrm{H}_{2} / \mathrm{kg}$ feed \\
\hline $\mathrm{MgO}$ & $43.1 \mathrm{~nm}$ & 44.9 & 0.6 & $2.7 \mathrm{H}_{2} / \mathrm{CO}_{2}$ mole ratio \\
\hline $\mathrm{Co} / \mathrm{TiO}_{2}$ & $7.7 \mathrm{~nm}$ & 32 & 0.1 & $0.6 \mathrm{~mol} \mathrm{H}_{2} / \mathrm{mol} \mathrm{C}$ reacted \\
\hline $\mathrm{Co} / \mathrm{ZrO}_{2}$ & $9.3 \mathrm{~nm}$ & 42 & 0.2 & $0.7 \mathrm{~mol} \mathrm{H}_{2} / \mathrm{mol} \mathrm{C}$ reacted \\
\hline
\end{tabular}


Residence time and biomass concentration at the reactor inlet have also a significant impact on product yields. The product yields typically increase with the residence time and decrease with the concentration, depending on the investigated range. For instance, the impact of residence time is insignificant at the 5-12-s range in SCWG of black liquor while further increase up to $120 \mathrm{~s}$ improves the yields [56]. However, the increases in the yields become smoother with increasing residence time at a very long residence time. In addition, long residence time at high temperatures causes char formation through repolymerization in SCWG processes [50]. Moreover, a very dilute reactor inlet (less than $10 \%$ by weight) results in a majority of the carbon in feedstock being converted to the aqueous organics in HTL processes [64].

The constituents in the feedstock play an important role in the impacts of process conditions on the reactions and product distribution. Cellulose, starch, and hemicellulose start to decompose already at $180-200{ }^{\circ} \mathrm{C}$ [64]. In contrast, proteins decompose very slowly at temperatures less than $230{ }^{\circ} \mathrm{C}$ due to peptide bonds being more stable than cellulose glycosidic bonds [64]. Moreover, lignin is the least reactive constituent of biomass, decomposing at 280-300 ${ }^{\circ} \mathrm{C}[41,73]$. At $240{ }^{\circ} \mathrm{C}$ or above, the degradation of sugars is faster than hydrolysis, i.e., generating the intermediate organics [49,64]. In addition, lignin is stated as the main source of char formation through the repolymerization of phenolics in SCWG processes [74]. From the phenomena and kinetic modeling viewpoints, it is worth noting that the reaction mechanism and kinetics were investigated through both model compounds and real biomass. Tables 2 and 3 compile some examples of literature studies on SCWG and HTL processes of various biomass together with the concluding remarks. It is crucial to understand the interactions among the constituents when processing real biomass. However, despite the overall understanding of reaction mechanisms and the impacts of process conditions, kinetic modeling of hydrothermal biomass conversion involves difficulties due to multiple constituents interacting with each other (e.g., carbohydrates being hydrogen donor for lignin decomposition $[75,76])$, extractives, and minerals affecting the product yields, very complex phenomena, and numerous intermediate compounds $[43,77]$. Therefore, when assessing the techno-economic feasibility, experimental investigations are specifically needed for product yields with respect to various combinations of process conditions and each biomass type or mixtures of biomass types occurring as feedstocks. For instance, hydrothermal co-liquefaction was investigated to reduce nitrogen content in bio-oil in the case of nitrogen-containing feedstock (e.g., sewage sludge, manure, or food waste), resulting in improved yields and less nitrogen compared to a single feedstock $[78,79]$. In contrast, mixing plastic and food wastes had a negative impact on energy efficiency in the SCWG process [80].

The experiments on SCWG and HTL are conducted in batch and continuous modes. The batch experiments provide simplicity for investigating the impacts of conditions on product yields: easier to conduct with less operational concerns of reactor plugging and pressurizing and pumping the feedstock [90]. For instance, some batch investigations involve an autoclave reactor with a volume of $500 \mathrm{~mL}$ [91], a stainless-steel vessel with a volume of $100 \mathrm{~mL}$ [92], a Hastelloy reactor with a volume of $200 \mathrm{~mL}$ [80]. However, despite being simple and suitable for qualitative analysis, the batch reactors involve techno-economic issues regarding scaling up to industrial applications [93]. Using catalysts in a batch reactor is limited due to the lack of mass transfer [94]. Moreover, the heating rate for reaching the reaction temperature strongly influences the product yields and reaction rates, especially when investigating short residence times. In addition, the process conditions do not remain constant during the operation, thus introducing difficulties in distinguishing the impacts of each condition [69]. For example, pressure increases with temperature besides the influence of heating rate. Consequently, it is not accurate to make quantitative comparisons between the yields in batch and continuous operations. Continuous operations are techno-economically more efficient for industrial applications provided that the operational issues are addressed effectively.

The optimum conditions are determined based on the compromise between the yields and costs, from the technoeconomic assessment viewpoint. The reactor inlet concentration determines the equipment size and energy requirement for high pressure and high temperature while affecting the product yields as well. Dilute inlets cause higher energy demand and larger equipment despite improving the yields. Temperature also affects the energy demand while improving the process. Nevertheless, the increasing temperature usually improves the energy efficiency of the process because of enhanced yields and heat integration. The residence time and reactor material have a direct impact on the reactor cost. Increasing the residence time causes higher reactor costs while improving the yields as well. However, after some optimum values, increasing the residence time further increases the reactor costs more intensively than improving the product yields. The alkali addition can be conducted as a homogeneous catalyst dissolved in the reaction mixture; however, despite improving the bio-oil yield, homogeneous catalysts introduce separation and recovery challenges [88]. Instead, heterogeneous catalysts are suitable for bio-oil production because of easy recovery, noncorrosivity, and higher thermal stability [88]. The pressure is maintained above the vapor pressure at the reaction temperature in HTL processes. On the other hand, high pressure causes a need for tough equipment, e.g., thicker reactors 


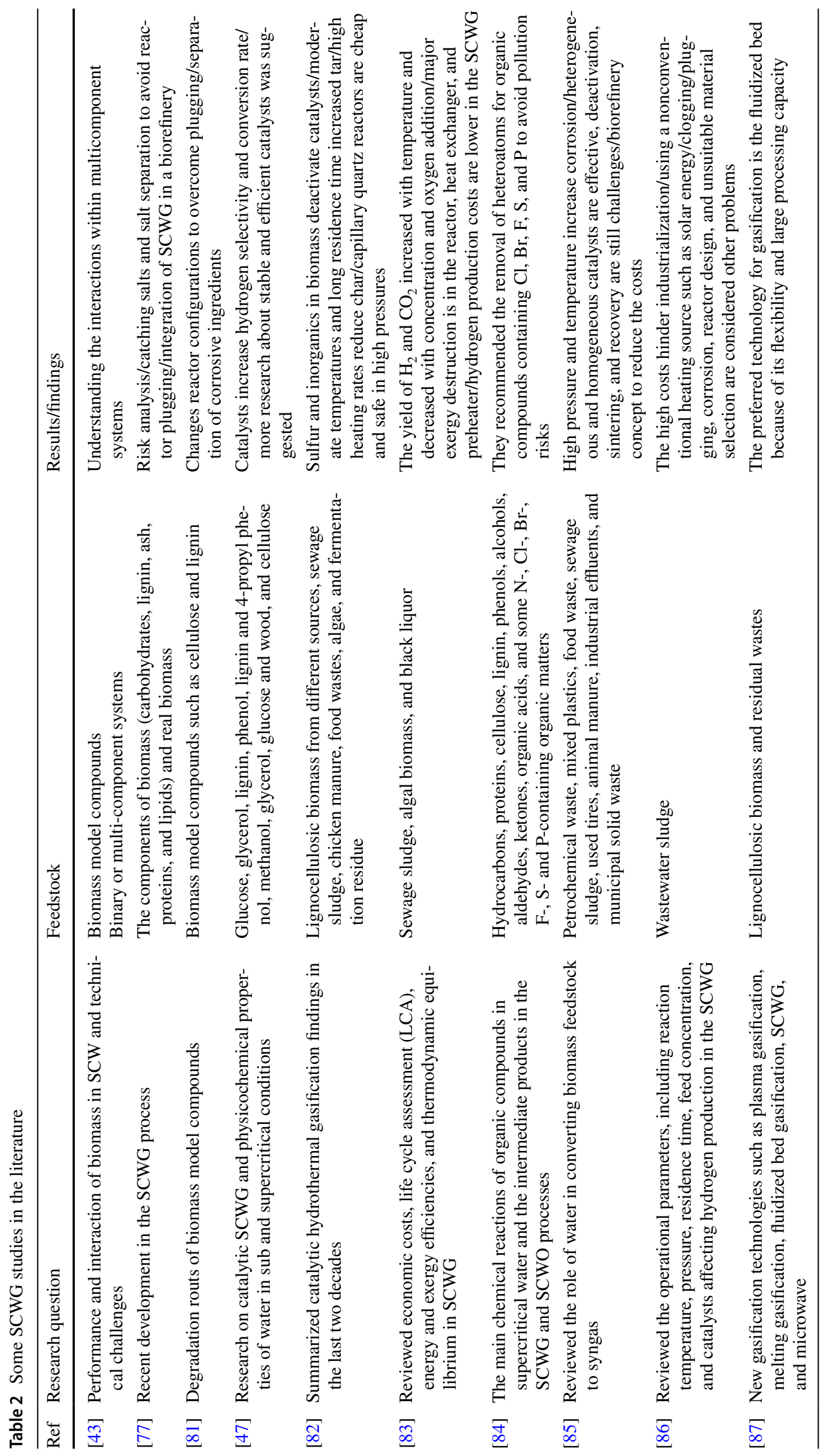




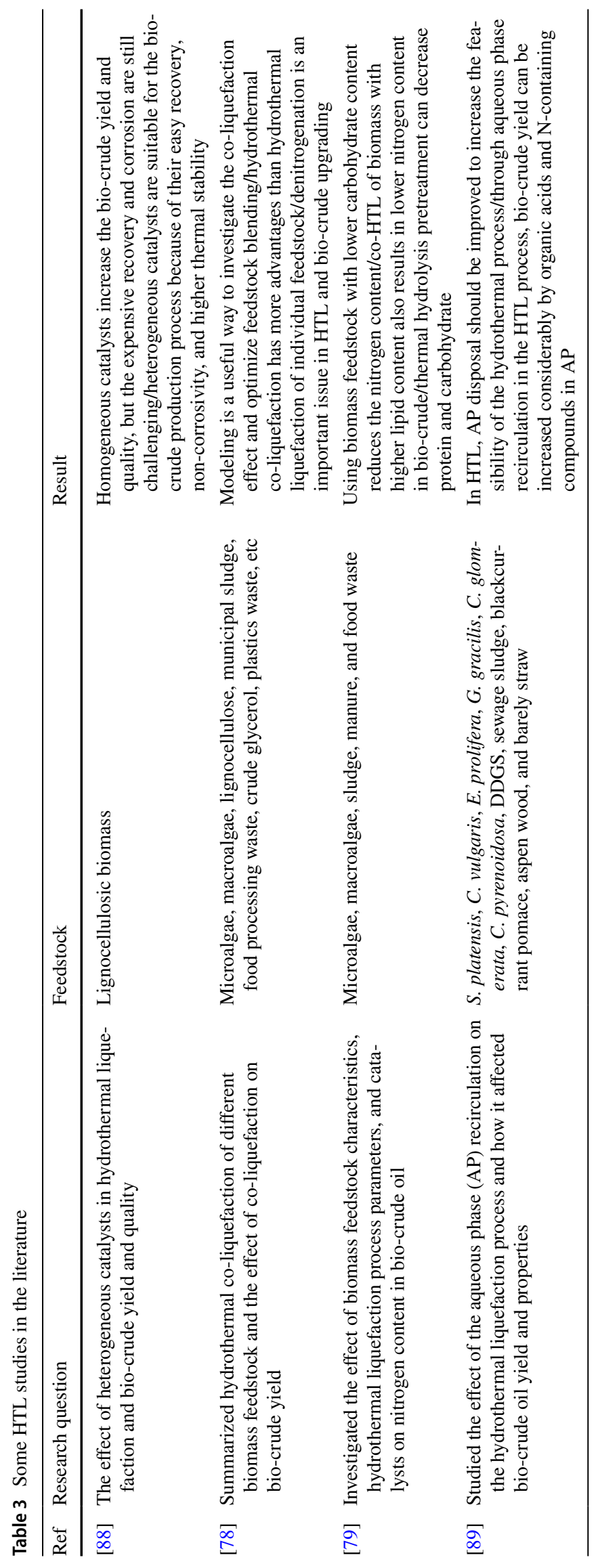


and other process units as well as more energy required in feed pumps. Similarly, the pressure is maintained slightly above the critical pressure of water in SCWG processes, e.g., $25 \mathrm{MPa}$. Consequently, the promising conditions for HTL involve temperature of $300-350{ }^{\circ} \mathrm{C}$, pressures of 4-20 MPa, reactor inlet concentration of $20-30 \%$ by weight, and residence times of 15-30 min. Meanwhile, the promising conditions for SCWG involve temperature of $600-750{ }^{\circ} \mathrm{C}$ (or $400-600{ }^{\circ} \mathrm{C}$ possible with transition metal catalysts), pressures of 23-25 MPa, reactor inlet concentration of 5-10\% by weight, and residence times of 1-5 min.

The techno-economic assessments indicate SCWG and HTL processes being promising for industrial applications among the biomass conversion processes while still resulting in more expensive costs compared to fossil-based processes. For instance, SCWG is more beneficial than thermal gasification as an alternative treatment for black liquor [38]. The minimum selling price of hydrogen was calculated as low as $1.46 € / \mathrm{kg}$ (price in 2018) in a preliminary feasibility study of integrating SCWG of black liquor in a pulp mill, based on the yields of lab-scale experiments [95]. Another study showed that integrating SCWG to a pulp mill can reduce the minimum selling price of air-dried pulp up to $22 \%$ [96]. In addition, the minimum selling price of hydrogen was calculated as $1.94 \$ / \mathrm{kg}$ (price in 2019) for a stand-alone SCWG process converting soybean straw [97]. SCWG process provides a competitive minimum selling price of hydrogen compared to other renewable processes (such as water electrolysis and thermochemical water-splitting cycles) and has potential for further improvements [83]. Similarly, the HTL process provides liquid fuel production with more efficient economic performance than pyrolysis. For instance, in a detailed report conducted in 2014, the biocrude oil costs were calculated as $16 \$ / G J(0.23 \$ /$ ton $)$ for pyrolysis while the cost was $14.5 \$ / G J(0.45 \$ /$ ton $)$ for HTL in case of processing forest residue [98]. Despite higher prices per mass, HTL provides cheaper prices in terms of energy content in the bio-oil. This results from HTL oil having significantly less oxygen content than pyrolysis oil [41]. The difference in oxygen content influences the upgrading process as well: HTL oil requires less hydrogen than pyrolysis oil. Consequently, the prices of liquid fuel were reported as $26.3 \$$ /
GJ or 3.09 \$/gallon gasoline-equivalent (1.1 \$/ton) for the pyrolysis process and as $16.9 \$ / G J$ or $2.00 \$ /$ gallon gasolineequivalent (0.71 $\$ /$ ton) for the pyrolysis process [98]. On the other hand, SCWG and HTL processes are not competitive yet compared to fossil-based productions. For instance, the production of hydrogen through SCWG can cost three times of hydrogen production through methane steam reforming of natural gas [99]. Similarly, the liquid fuel production through HTL was also reported to be uncompetitive compared to petroleum-based gasoline [100]. Currently, SCWG and HTL technologies are available on pilot scale to investigate the possibilities for improving the economic performances and for addressing the operational issues [68, 101-104].

The industrialization of SCWG and HTL processes requires addressing the operational issues as well as improvements in economic performance. These processes introduce operational issues due to extraordinary pressure and temperature conditions causing changes in water properties. The main operational issues include process safety matters due to extraordinary conditions, plugging, corrosion, pumpability of feedstock, and catalyst deactivation. These issues can reduce the techno-economic performances calculated in the feasibility studies for industrial capacities: reducing the product yields over time (e.g., due to catalyst deactivation), increasing the maintenance costs (e.g., corrosion and plugging), and introducing constraints to the conditions when optimizing the processes (e.g., reactor inlet concentration limited by pumpability limits).

\section{Operational issues of SCWG and HTL processes}

The operational issues hinder the industrialization of SCWG and HTL in a continuous mode through various effects on the processes, such as causing process safety issues, reducing the economic performance, or even ceasing the operation. Therefore, these issues can be addressed by investigating the root causes of each, the impacts on the process, and the possible solutions together. This article reviews the operational issues through a roadmap shown in Fig. 1. The main operational issues include the following:
Fig. 1 Article structure and parameters studied. (Top) Supercritical water gasification operational issues. (Bottom) Hydrothermal liquefaction operational issues
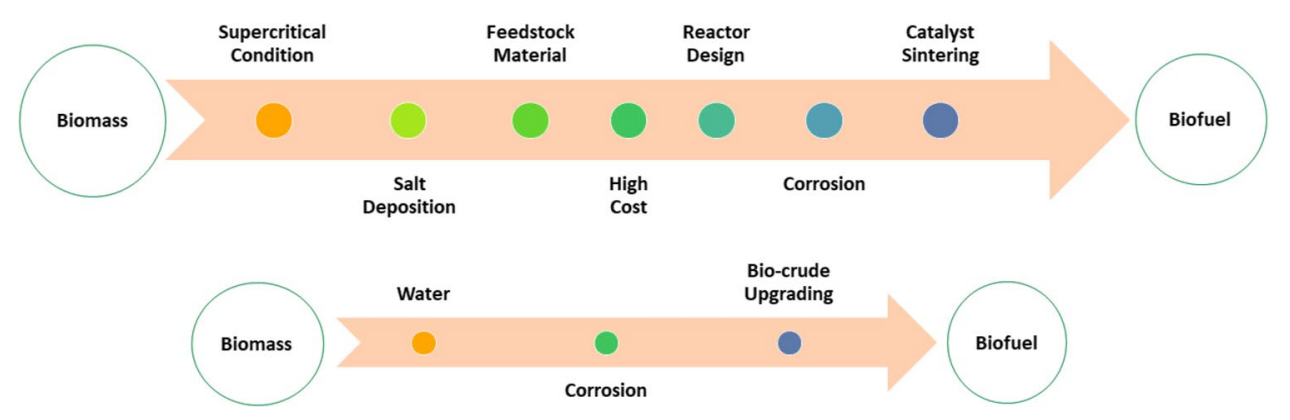
- Process safety matters due to mechanical stress on the reactor

- Plugging due to solid deposition versus reactor configuration

- Corrosion due to inorganic content and water dissociation

- Pumpability of feedstock versus concentration

- Catalyst deactivation versus catalyst types

- Production costs versus biorefinery concepts

- Product quality and further upgrading/synthesis

\subsection{Process safety versus operation conditions}

High temperature and pressure may cause accidents during the operation due to changes in the properties of the reactor and pipeline material. The possible accidents include fracture, rupture, or burst of a pipeline or the reactor. Therefore, the mechanical properties become essential for a long-term operation at high pressure and temperature. The burst pressure is calculated based on the ultimate tensile strength of the material and the ratio of outer diameter to the wall thickness [105]. However, the burst pressure is usually calculated for a flawless material and reduces with fatigue, corrosion, and fractures on the microstructure of the material [106]. As a rule of thumb, it is suggested to operate under the pressure one-fourth of the calculated burst pressure [107]. For instance, the outer diameter-to-wall thickness ratio of stainless steel can be a maximum of around 12 for operating at 250 bars, according to the correlation derived by $\mathrm{Oh}$ et al. (2020) [105] and using working pressure as four times the calculated burst pressure. The ultimate strength of stainless steel was reported as $565 \mathrm{MPa}$ while that of Inconel 625 is $714-1103 \mathrm{MPa}[105,108]$. In addition, there is a need for pressure-relieving devices as a safety precaution, and the reliability of those devices becomes an issue for fluids containing also solid at high temperature and pressure [109]. Furthermore, the thermal stability of the materials is also an important parameter for long-term operations. Inconel material has good thermal stability at temperatures over $1000{ }^{\circ} \mathrm{C}$. On the other hand, stainless steel $316 \mathrm{~L}$ was reported to be stable up to $650{ }^{\circ} \mathrm{C}$ regarding ductility, yield strength microstructure [110], despite experimental studies of SCWG conducted in stainless steel $316 \mathrm{~L}$ reactor at $700-750{ }^{\circ} \mathrm{C}$ [39]. Nevertheless, the thermal stability of other stainless steel types has been improved enabling the usage at temperatures up to $1150{ }^{\circ} \mathrm{C}$ through adjusting ferric and chromium contents [111].

Besides high temperature and pressure, the sudden variation of these two conditions can provoke disastrous effects as observed in the lab-scale experiments [106, 112]. The variations of temperature and pressure result from sudden mass injection into SCW conditions and partial plugging due to solid deposition in the reactor. A sudden mass injection into the reactor at supercritical conditions results in a fast expansion, which stresses the reactor metal [106]. Moreover, the fast injection of mass could also provoke a contraction of the reactor walls, which would also concern the locking system, as demonstrated in Fig. 2. At that high pressure, any variation of the metal properties might cause the reactor to release a quantity of material outside. Therefore, the reactor should certainly be shielded for hydrothermal conversion operations. In laboratory conditions, this protection is usually given to the operator by Plexiglas. Furthermore, semibatch (i.e., stepwise injection) operations are conducted with low flow rates in the laboratory scale to avoid sudden and fast mass injections [39, 40]. Solid deposition in the reactor also causes variations in pressure and temperature due to partial plugging and control actions of the pressure valves. The solid deposition is addressed by optimizing the process conditions to minimize the char formation and applying special reactor configurations enabling the separation of solids, as determined in Sect. 3.2.

\subsection{Plugging due to solid deposition versus reactor configuration}

Solid-phase occurs due to the precipitation of salts in the feedstock and char formation in hydrothermal processes. The solubilities of salts decrease with temperature in hot compressed water, even to the magnitudes of ppm at SCWG temperatures $[73,113]$. This causes precipitation of salts, especially in SCWG processes. The nature of the salt also affects its behavior in supercritical conditions [114]. The salts are classified as type I and type II based on melting points $[115,116]$. The melting temperature of type I salts is between 800 and $1000{ }^{\circ} \mathrm{C}$, and their solubility is slightly higher in supercritical conditions. Meanwhile, type II salts have melting points between 700 and $800{ }^{\circ} \mathrm{C}$ and are less soluble in hot compressed water $[114,115,117$, 118]. Table 4 exemplifies type I and II salts occurring in

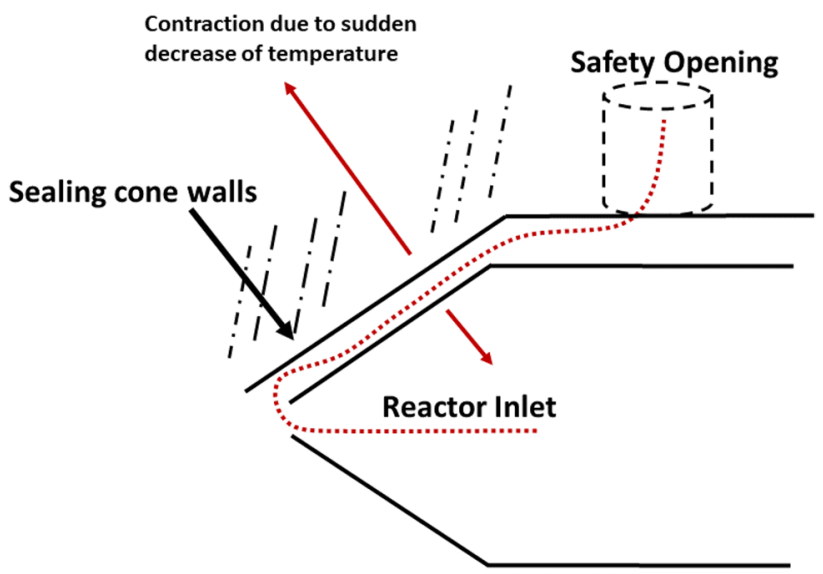

Fig. 2 Fast injection of mass effect in the reactor inlet and walls 
Table 4 Type I and II salts and their characteristics

\begin{tabular}{lllll}
\hline Salt component & Type & $\begin{array}{l}\text { Tempera- } \\
\text { ture }\left({ }^{\circ} \mathrm{C}\right)\end{array}$ & Pressure (bar) & Ref \\
\hline $\mathrm{KOH}$ & I & 460 & v.p & {$[123]$} \\
$\mathrm{NaOH}$ & I & 550 & v.p & {$[124]$} \\
$\mathrm{K}_{2} \mathrm{CO}_{3}$ & I & 450 & v.p & {$[125]$} \\
$\mathrm{LiOH}$ & I & 420 & v.p & {$[126]$} \\
$\mathrm{Na}_{2} \mathrm{CO}_{3}$ & II & 540 & 300 & {$[127]$} \\
$\mathrm{Na}_{3} \mathrm{PO}_{4}$ & II & 450 & 1560 & {$[128]$} \\
$\mathrm{Na}_{2} \mathrm{SO}_{4}$ & II & 500 & 1500 & {$[117]$} \\
\hline
\end{tabular}

"v.p." means that the phase equilibria were studied at saturated vapor pressure

supercritical water gasification of biomass [114, 116]. Type II salts cause plugging more intensively because of forming crystals instantly (also referred to as shock crystallization [119]) and sticking the hottest part of the wall while type I salts can remain as brines $[118,120,121]$. Nevertheless, the mixtures of salts behave differently from salt-water binary systems at SCW conditions; e.g., a mixture of type II salts can form type I salts [120]. For instance, the precipitated salts mainly include sodium sulfate and sodium carbonate in the case of SCWG of Kraft black liquor [112]. The other source of solid phase is char formation during biomass decomposition. Despite hydrothermal decomposition being more dominant, char is formed through pyrolysis of unhydrolyzed lignin when processing lignocellulosic feedstocks [53, 122]. Depolymerization of lignin in SCW occurs only in a few seconds but results in high char yield, i.e., char formation already at the entrance of the reactor [60]. In addition, char is formed also throughout the rector due to the repolymerization of phenolics and aromatic intermediates at high temperatures and long residence time [39, 50, 53, 122].

The solid deposition is an obstacle for SCWG processes due to introducing the risks of plugging at the reactor inlet and rupture of reactor wall $[106,112]$. In a continuous operation with an isothermal reactor, the feedstock reaches SCWG conditions immediately at the reactor inlet, thus precipitating salts and char at the reactor inlet. This causes partial plugging and variations in pressure, thus introducing the safety issues mentioned in Sect. 3.1 and ultimately causing the interruption of the operation. For instance, as experimented by De Blasio et al. (2019) [112] in a plug-flow reactor, SCWG of Kraft black liquor was interrupted at $600{ }^{\circ} \mathrm{C}$ due to solid deposition and plugging while SCWG of sucrose was successfully conducted at $500-700{ }^{\circ} \mathrm{C}$. This observation determined the impact of biomass constituents as well. In the absence of lignin and salts, the solid phase involves only char in less amount, i.e., only aromatic ring compound as the heaviest compounds and possible to decompose [112]. On the other hand, a feedstock with lignin, salts, and ash results in precipitation of salts and ash, the species impossible to decompose, as well as more intensive formation of char [112]. Moreover, even in a successful operation, solid deposition on the reactor wall increases the corrosion risk (as investigated in Sect. 3.3) and decreases the heat transfer capability [43, 117, 129, 130].

Some investigated solutions to solid deposition include stepwise injection into the reactor and separation of salts prior to the reactor. The stepwise injection (semi-batch) results in the gradual transition of the injected mass to the reaction temperature. Temperature decreases at the entrance of the reactor after each injection then adjusted via controllers until the next injections. This transition provides gradual precipitation of salts and char throughout the reactor, rather than fast precipitation at the entrance [39]. In addition, char is partly consumed in gasification reactions until the next injection. As an additional parameter, the heating rate also influences the process in semi-batch or batch processes. A high heating rate reduces char and tar formation while causing faster precipitation of solids and more variation, i.e., less time at low temperatures and reaching the SCWG temperature faster. Meanwhile, a low heating rate reduces the temperature gradient and results in gradual precipitation while reducing the efficiencies and yields due to low temperatures at the bigger part of the reactor. In the stepwise injection method, the residence time can be adjusted by changing the pumping interval of injections. However, this method can result in lower yields and efficiencies than an isothermal reactor due to fluctuations of temperature at the beginning of the reactor. Although the stepwise injection enables experimental studies in lab scale with tubular reactors, the solid deposition would be inevitable regarding long-term operations in industrial applications. Therefore, separation of solids can prevent the plugging issue as well as recover the valuable inorganics. Another solution is to separate the salts prior to the reactor, at slightly above the critical temperature and with a very short residence time of around a second, e.g., PSI process [131]. This provides the recovery of valuable inorganics and separation of substances introducing an issue for the catalysts in downstream processes [121]. The alkali nitrates are destructive for the carbon-supported catalysts, and sulfur content can cause catalyst poisoning or dealloying of reactor walls [121, 132]. In addition, nutrients can be used as fertilizers, such as potassium, phosphorous, and nitrogen. However, alkali metals catalyze the gasification reactions, i.e., undesirable to separate in advance, and char formation also causes solid deposition (more intensively for lignocellulosic feedstock).

Other measures against solid deposition include optimizing the process conditions to minimize char formation and using hydrothermal brine. The hydrothermal brine (usually a potassium salt) can catch the other salts and precipitate to the bottom of the reactor [133]. To address plugging while 
capturing the salts, Wang et al. [134] patented a countercurrent tank-type supercritical water reactor with a sacrificial lining containing a cylinder body and a catalyst tank. Meanwhile, process conditions play an important role in minimizing char formation. For instance, as determined for SCWG of black liquor, char formation increases with residence time (in 2-5-min range) in stainless steel reactor at high temperature (e.g., $750{ }^{\circ} \mathrm{C}$ ) [39]. In contrast, the Inconel reactor suppresses the repolymerization reactions and resulted in less char formation in longer residence time at the same temperature [39]. However, residence time did not affect the char formation in the Inconel reactor at lower temperatures (e.g., $600{ }^{\circ} \mathrm{C}$ ) [39]. As a result, minimum char formation was obtained at high temperature $\left(750^{\circ} \mathrm{C}\right)$ and long residence time ( $5 \mathrm{~min}$ ) in Inconel reactor, the conditions also maximizing the thermal efficiency. Alternatively, stainless steel reactor provides minimum char formation at high temperatures with a short residence time.

The solid deposition and plugging issues can be addressed by special reactor configurations enabling solid separation. Some configurations were investigated originally for SCWO processes. A suggested configuration involves a vertical autoclave reactor of which the bottom is maintained at sub-critical conditions, thus dissolving the salts instead of precipitation [135, 136]. However, this configuration was reported to have scale-up issues [135]. Another design involves a horizontal autoclave reactor with a stirrer at the center [137]. The stirrer provides turbulent flow moving the salts with the fluid phase, instead of precipitation. This design was reported to succeed for feedstock with less than $6 \%$ organic content and less than $4 \%$ salt content in the case of SCWO, i.e., burning the content [137]. On the other hand, this design might not be applicable for solid deposition to a higher extent through salts and char formation simultaneously, as in SCWG processes. Another approach to the plugging issue is to manipulate the reactor wall only, but not the reaction zone, to prevent the precipitation of solids on the wall. For instance, a design involves a reaction chamber operating at $800{ }^{\circ} \mathrm{C}$ while the wall is maintained at $400{ }^{\circ} \mathrm{C}$ to prevent corrosion over the reinforced stainlesssteel shell as designed and modeled by Cocero and Martinez (2004) [138]. As another way to manipulate the reactor wall, a design succeeded in lab scale consists of a transpiring-wall reactor (TRW) to address the plugging and corrosion problems $[139,140]$. This reactor configuration avoids the contact of solids to the reactor wall by forming water film on the surface via porous, non-load-bearing cylindrical transpiringwall elements. However, manipulating the reactor wall can cause heat transfer issues and reduction in gas yields due to temperature gradient in the reactor, despite being conducted for the exothermic SCWO process. Further designs were developed also specifically for the SCWG process. A proposed design configured a vertical tubular reactor, the reactor inlet entering from the top, and the product outlet from the bottom as shown in Fig. 3; however, this configuration caused plugging in the feed line of the condenser [141]. To address this problem, another design tilted the gasification reactor to $75^{\circ}$ from a vertical position as shown in Fig. 4, positioning the inlet of the reactor at the bottom and the outlet of the reactor at the top (down-up configuration) as well as involving insulation and a cooling zone [142]. According to their results, the down-up configuration resulted in higher gas yield, carbon gasification efficiency, and higher hydrogen yield than the up-down configuration. Another way to prevent plugging is to use a fluidized bed reactor, providing easier continuous solid handling [90]. It can attain the same residence time values as those achieved in the traditional SCWG of biomass while improving mixing characteristics. For instance, Matsumura and Minowa (2004) [90] considered two operational modes for large and small particle size,
Fig. 3 Simplified Veriansyah reactor design [141]

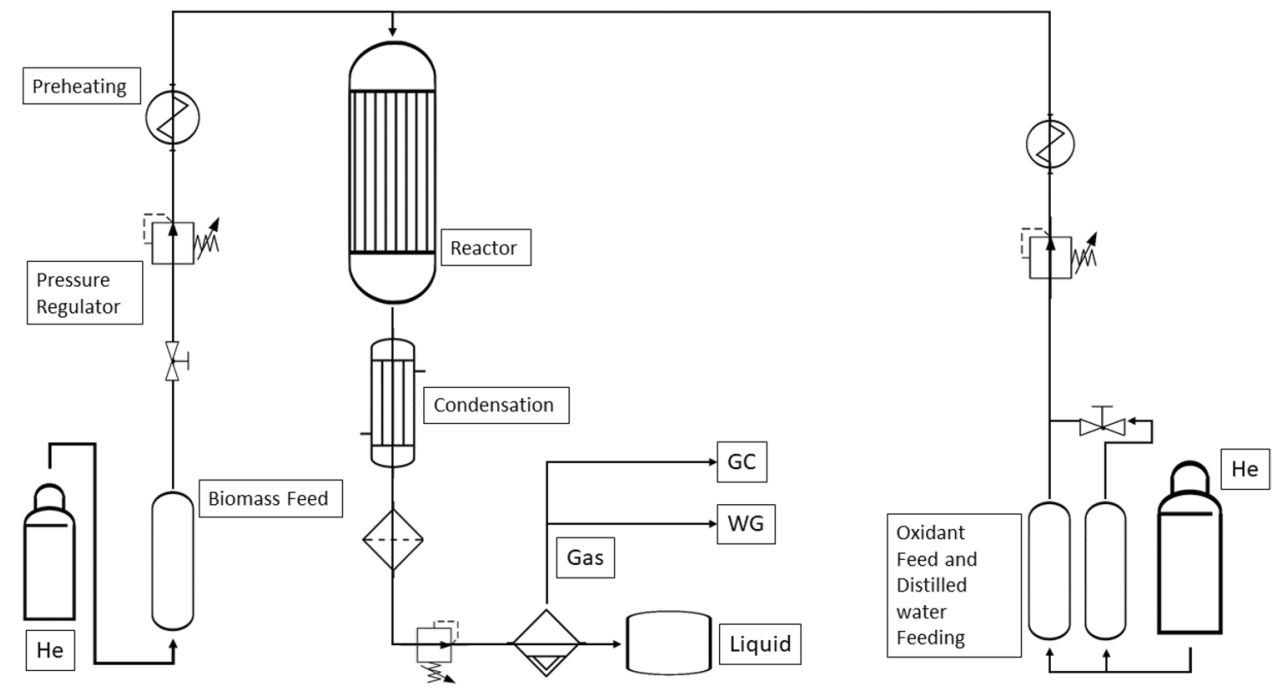


Fig. 4 Susanti et al. reactor simplified configuration [142]

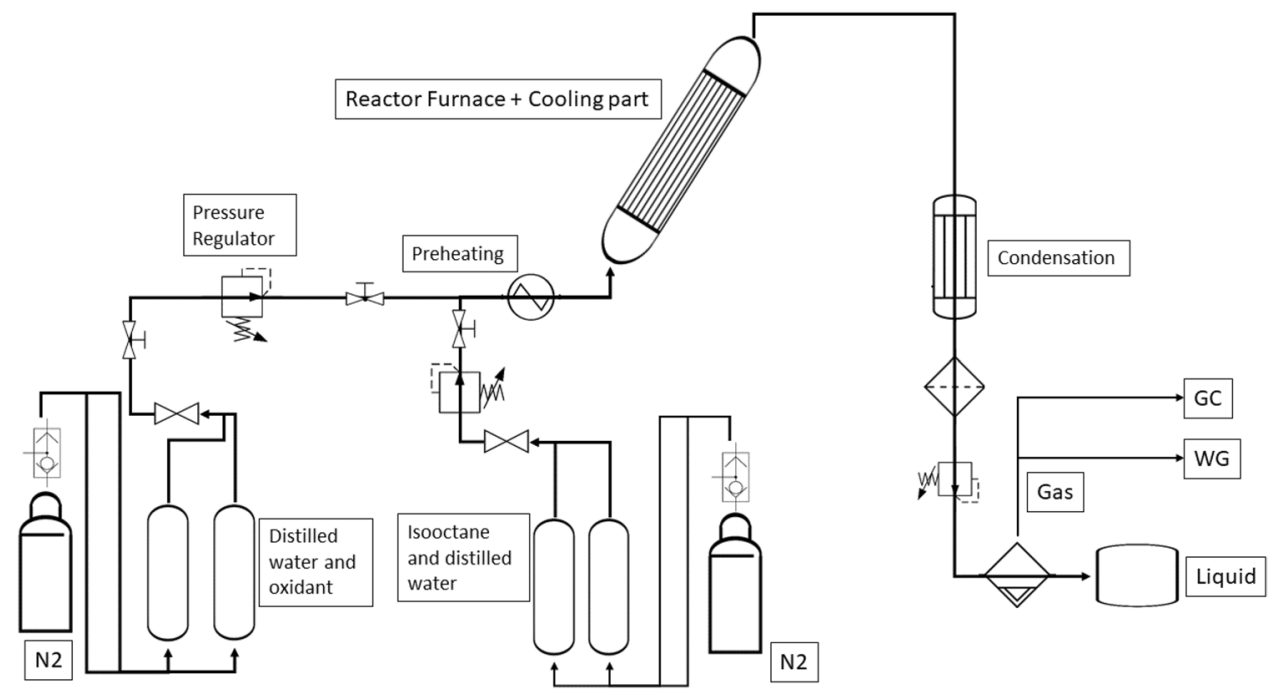

bubbling/particulate bed operation for larger particle size and circulating fluidized bed for smaller particle size. Based on their results, a low-velocity bubbling fluidized bed is the optimal flow regime. Jin et al. (2010) also used a fluidized bed reactor for SCWG of coal as shown in Fig. 5 to prevent plugging issues occurring in tubular reactors. According to their results, the fluidized bed reactor enhanced mass and heat transfer in the reactor and consequently improved gasification efficiency without blockage problems. Another approach is a reactor configuration simultaneously enabling solid separation as another outlet. For example, the Verena pilot plant has a vertical pressure vessel reactor with a feedline from the top, a riser tube having an outlet at the top, and another outlet at the bottom of the reactor [101, 143]. The feedstock enters the reactor from the top and moves downwards. Then, the formed gases move upwards through the riser tube while solids precipitate towards the outlet at the bottom because of higher density.
The HTL process has less risk of plugging than SCWG because of higher solubilities of salts and less char formation under HTL conditions. Plugging was reported as a minor issue and can be controlled via a pressure letdown valve [145]. Therefore, reactor configuration is not a major concern in HTL processes. For instance, Guo et al. (2019) [146] conducted HTL of two strains of microalgae in a continuously stirred tank reactor at $24 \mathrm{MPa}$ and $35^{\circ} \mathrm{C}$ with a residence time of $15 \mathrm{~min}$. Figure 6 shows the flow diagram. Nevertheless, the char formation can be reduced further by using co-solvent in HTL processes. The co-solvents increase bio-oil yields by improving the dissolution and hydrolysis of macromolecules and preventing repolymerization to char [147-150]. Some common co-solvents include glycerol, ethanol, methanol, and acetone. The influence of glycerol increases with the presence of alkali metals, resulting in more increase in bio-oil yield compared to the absence of alkali metals [148]. As illustrated by processing lignin and
Fig. 5 The schematic diagram of the Jin et al. system [144]

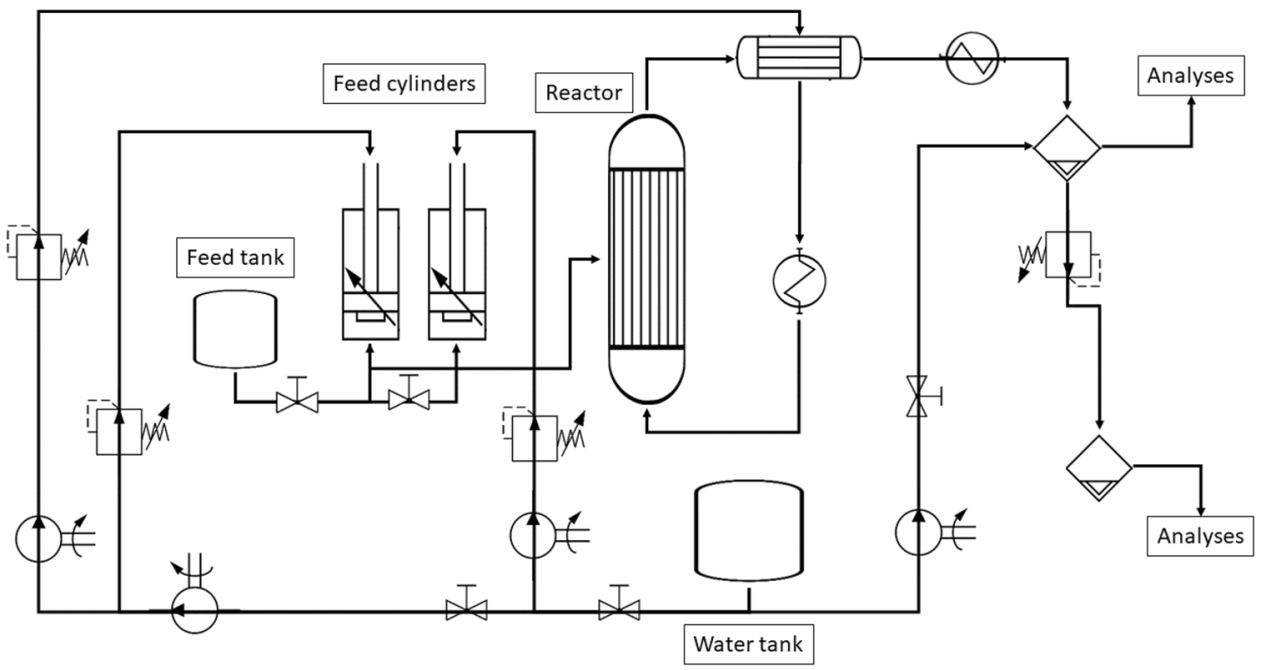


Fig. 6 Guo et al. flow diagram [146]

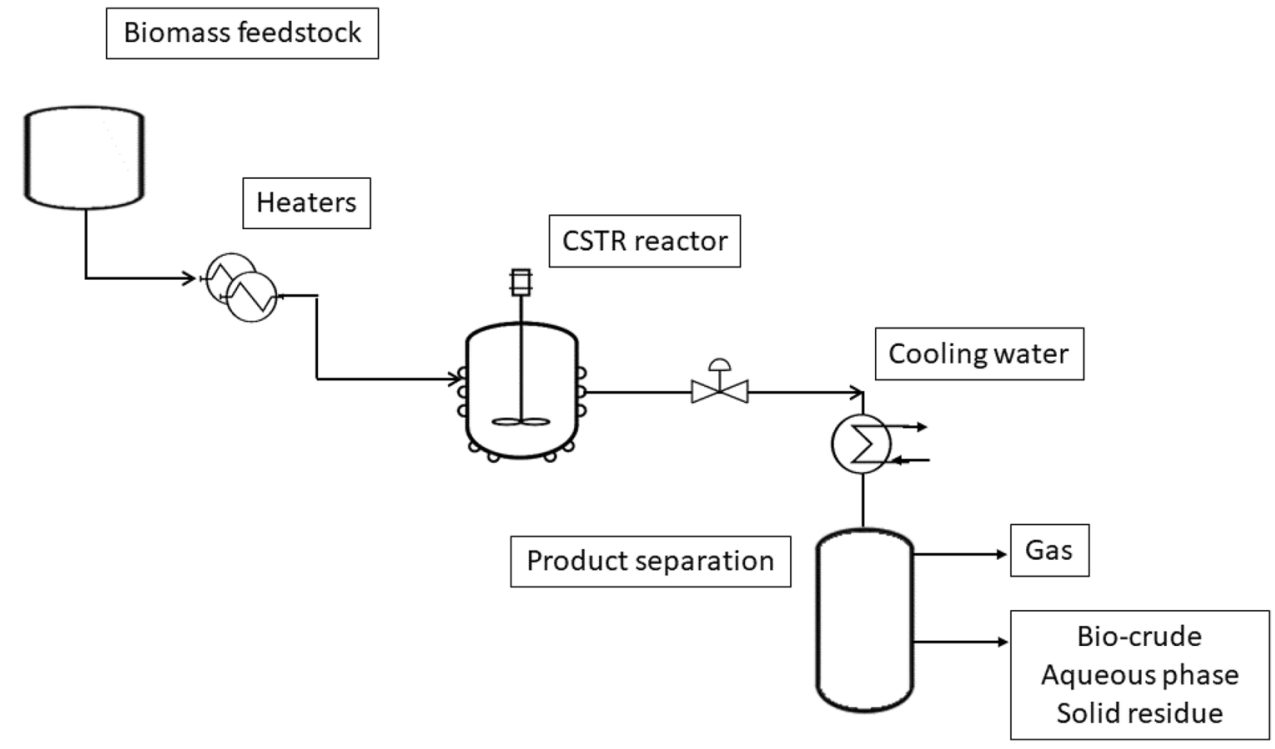

lignin/cellulose mixture, ethanol/water mixture increased the bio-oil yields by enhancing the hydrolysis and preventing repolymerization of lignin fragments [150]. In fact, ethanol was stated as a suitable co-solvent for any feedstock in HTL processes [150].

\subsection{Corrosion types and the proposed solutions}

The hydrothermal processes result in corrosion due to exposure of reactor walls and pipelines to hot compressed water, char, and alkali salts [94, 151]. The corrosion types can be classified as electrochemical and chemical corrosions. Electrochemical corrosion is a major concern in the HTL process due to the high density and polarity of water, i.e., ionic reaction mechanisms with a high concentration of hydroxide and hydronium ions as well as ions of salts [64]. In addition, the HTL process generates oxygenated compounds such as organic acids, contributing to electrochemical corrosion [145]. Chemical corrosion can occur through various phenomena including general corrosion, under-deposit corrosion, dealloying, intergranular corrosion, pitting, hydriding, and stress corrosion cracking [145, 152]. General corrosion refers to the relatively uniform degradation of metal surface material at a predictable rate. The under-deposit corrosion occurs when solids precipitate on a metal surface, thus being a major issue in SCWG. This can cause a microenvironment between the metal surface and the bulk fluid, resulting in more corrosive conditions in the microenvironment. Dealloying refers to an alloy component selectively being oxidized and dissolved under operating conditions. Dealloying can occur due to alkaline conditions or the presence of sulfide. The intergranular corrosion occurs at the metal grain boundaries in the presence of chloride, sulfate, and/ or nitrate. The pitting is a localized and extensive version of corrosion occurring in the presence of chloride and sulfate under sub-critical water conditions or in the presence of chloride under SCW conditions, thus being a concern both for HTL and SCWG [151]. This corrosion might occur in stainless steel and nickel-based alloys; nickel-based alloys were stated to be more resistant to pitting than stainless steel [151]. In contrast, pitting does not occur in titanium reactors due to chloride or sulfate; however, titanium reactors have less mechanical strength [64]. Moreover, hydriding is a corrosion type associated with titanium in the presence of phosphate salts, which can result in hydrogen embrittlement: phosphate reacting with titanium dioxide layer, bare titanium reacting with water to reform the oxide, hydrogen penetrating into the titanium, and forming hydride [151]. The stress corrosion cracking occurs in the presence of mechanical stress on the material together with corrosive species. The mechanical stress can result from thermal expansion, weight loads, and bend points in piping as well as internal pressure.

Prior to industrial applications, it is crucial to investigate corrosion in SCWG and HTL processes with respect to biomass constituents, process conditions, and reactor materials. For instance, Hirose et al. [153] investigated stress corrosion cracking susceptibility and corrosion behavior of ferritic/ martensitic steel $\mathrm{F} 82 \mathrm{H}$ at $287-543^{\circ} \mathrm{C}$ and $23.5 \mathrm{MPa}$ supercritical pressurized water (SCPW) in Inconel625 sleeve. According to their results, F82H was the barrier between the iron-rich layer and the chromium-rich layer. Moreover, weight gain increased with temperature. Nevertheless, no signs of cracking or exfoliation were observed on the surface, and the weight gain resulted from iron-rich oxide. Similarly, $\mathrm{Fe}-\mathrm{Cr}-\mathrm{Si}$-rich oxide(s) was observed also on various alloys in the HTL process, including 410 ferritic stainless steel, conventional-type 300 series austenitic stainless steels of varying $\mathrm{Ni}, \mathrm{Cr}$, and Mo content (301, 304L, 316L, 
317L, and 347), low-Ni, high-Mn austenitic such as grades 201 , and related alloys, higher-Ni austenitic $(310,800,904 \mathrm{~L}$, and related high $\mathrm{Ni}, \mathrm{Mo}, \mathrm{Cr}$ grades), and the $\mathrm{Ni}$-base alloys 600 and 825 [154]. Moreover, small quantities of $\mathrm{Na}, \mathrm{K}, \mathrm{Cl}$, and $\mathrm{Ca}$ were also detected on those materials in the same investigation. $\mathrm{S}, \mathrm{Na}$, and $\mathrm{Cl}$ species caused corrosion and cracking while higher alloy $\mathrm{Ni}, \mathrm{Cr}$, and Mo contents are more resistant against corrosion. However, in the case of the existence of sulfur in the reactor, costly high-Ni alloys may not be the solution due to the risk of sulfidation attack. Therefore, Brady et al. (2014) [154] suggested reducing the nickel content and increasing the proportion of chromium and manganese in the austenitic steel, such as grade 201. Exposing nickel alloy 625 to SCW, another study also observed mass gain of $0.15 \mathrm{mg} / \mathrm{cm}^{2}$ after 1000 -h operation due to oxide particles at $600{ }^{\circ} \mathrm{C}$ while not observing significant mass change at 400 and $500{ }^{\circ} \mathrm{C}$ [155]. The surface morphologies also showed the size of the oxide particles on the outside surface increased with increasing test duration. Moreover, pits were also observed on the surface at 400 and $600{ }^{\circ} \mathrm{C}$ with a size of $4.3 \mu \mathrm{m}$ and $8 \mu \mathrm{m}$, respectively. It can grow to $12.9 \mu \mathrm{m}$ at $400{ }^{\circ} \mathrm{C}$ depending on the test duration, but no significant changes were observed at $600{ }^{\circ} \mathrm{C}$.

The corrosion issue can be addressed through different approaches: optimizing the process conditions together with reactor material selection for minimum char formation, reactor configurations preventing solid species from contacting the surface, adjusting the feedstock, and adjusting the effluent [151]. Regarding the process conditions, the char formation can be reduced by optimizing the temperature, residence time, and reactor material together as well as involving catalysts, as determined in Sect. 3.2. Regarding the reactor materials, the materials stated as corrosion-resistant include stainless steels, nickel alloys, titanium, tantalum, noble metals, and ceramics [156]. Among those materials, nickel alloys (e.g., Inconel and Hastelloy), titanium, and stainless steel were the most used reactor materials because of catalytic impacts and economic aspects. The corrosion resistance of these materials depends on temperature and the species present in the reaction mixture. Nickel alloys were reported to be more corrosion-resistant and to have high strength for SCWG processes at high temperatures as well as being more catalytic while stainless steel can be more suitable to HTL processes because of higher corrosion resistance and lower cost $[151,156]$. Ni alloys such as Inconel 625, Hastelloy C-276, and titanium are the most used materials to reduce corrosion [64]. Calzavara et al. (2004) [137] designed a new reactor in which there is double-shell titanium in the reactor to prevent corrosion. This new concept was suitable to prevent corrosion, observing no corrosion trace after a longrunning time on the double shell. As another approach, some reactor configurations were designed to prevent corrosive species from contacting the surface. An applicable method involves the "vortex/circulating flow reactor" in which fluid motion is applied to compel the hottest environment away from the shell [151]. Other methods include transpiring wall reactor and cool wall reactor, also used to address the plugging issue as mentioned in Sect. 3.2. However, these methods have issues regarding industrial-scale applications. The other approach is to adjust the feedstock by mixing the corrosive feedstock with another non-corrosive feedstock and pre-neutralization. The pre-neutralization involves neutralizing the acidic or alkaline feedstock to address the electrochemical corrosion, relevant for HTL processes. The mixing method would at least reduce the concentrations of corrosive species, especially sulfur and chloride contents.

\subsection{Pumpability of the feedstock versus concentration}

One of the main challenges regarding biomass feedstock management is pumping the highly concentrated and twophase biomass feedstock in supercritical and subcritical conditions. In addition, the feedstock concentration varies during the operation as well as occasionally containing solid particles $[129,157,158]$. The dry matter content in the biomass feedstock should be within the pumpability limits of high-pressure pumps to avoid clogging problems while optimizing the product yields versus the energy required to heat the feedstock. Otherwise, the feed may not be a steady flow into the reactor [159]. Moreover, in the case of rector clogging during SCWG of high concentrated feedstock, there will be a high amount of biomass in the reactor continuing to gasify even after turning the heaters off or stopping the inlet flows.

The pumpability limit is directly affected by the nature of biomass feedstock and the target pressure [73, 160]. In addition, the particle size of solids may cause dewatering within the pump in the case of coarse particles. However, size reduction would be costly and energy-intensive for the feedstock of hydrothermal processes. Therefore, it is advised to test the considered pumps in the specific conditions of a process in scope (the specific feedstock to be processed with biomass type and particle size to be processed, and the target pressure) [160]. Nevertheless, the particle size does not have a significant impact on the process chemistry; therefore, it is sufficient to confirm the pumpability of the feedstock with its particle size [160]. In addition, a concentrated feedstock can also be mixed with a dilute waste to control the reactor inlet concentration, as applied in a SCWO pilot plant [157]. Furthermore, the aqueous phase after product separation can be recycled to the reactor in SCWG and HTL processes.

An assessment of commercial high-pressure pumps indicated that the pumpability limit for solid content decreases with the target pressure: $45 \%$ for 130 bars and $10-18 \%$ for 206-320 bars for lignocellulosic biomass [160]. All the 
assessed pumps were stated to have the ability to pump the finely ground woody feedstock up to $15 \%$ solid content; however, the industrial feedstocks have a higher particle size (2-4 mm or higher) and might require special design [160]. Nevertheless, the pumpability limit was reported as $22 \%$ for sewage sludge with a pump operating at 220-300 bars [160].

Currently, the process conditions are assessed within the pumpability limits. The optimum dry content usually has the range of $10-20 \%$ by weight for high hydrogen yields in SCWG processes, depending on the biomass type [161]. Meanwhile, HTL processes have feedstocks with higher solid contents at the optimum conditions, e.g., up to $35 \%$ $[162,163]$.

\subsection{Catalyst deactivation versus the catalyst type}

Catalyst deactivation is another issue regarding the process operation and economic performance. This issue causes a reduction in product yields and quality. Even though the feasibility studies are usually based on experimentally observed yields, catalyst deactivation reduces the product yields and quality significantly in long-term operations. Therefore, this issue is to be addressed for stable operation and optimum economic performance. Among the metals used for SCWG and HTL processes, nickel catalysts were stated to deactivate despite the high activity and cheap price [102]. As another alternative, ruthenium catalysts were stated to be more stable and to have higher activity; on the other hand, this catalyst is more expensive [102].

Catalyst deactivation can result from various phenomena including poisoning and thermal/chemical degradation as chemical deactivation as well as sintering and fouling as mechanical deactivation [164]. The poisoning occurs due to adsorption or chemisorption of intermediate organics to the catalyst surface in hydrothermal processes, thus blocking the active sites [165]. Chemical degradation refers to undesired reactions between the catalyst and the fluid or support, producing an inactive phase. Similarly, thermal degradation causes loss of surface area due to active phase-support reactions. As a mechanical deactivation, fouling refers to the deposition of unreactive species on the catalyst surface or in the pores. This becomes an issue due to the presence of char (in both HTL and SCWG processes) and salt precipitation (in SCWG processes). In addition, heterogeneous catalysts can be deactivated through sintering, i.e., the agglomeration of the catalyst particles causing a reduction in the surface area. Sintering might occur more likely at temperatures higher than $500{ }^{\circ} \mathrm{C}$ [164] while poisoning via intermediate organics becomes an issue at lower temperatures (e.g., in HTL processes or SCWG at $\left.400{ }^{\circ} \mathrm{C}[165,166]\right)$.

The approaches to address catalyst deactivation include new methods for catalyst synthesis, enhanced dispersion of the catalyst active site on the support, the addition of a transition metal in trace amounts, and bimetallic catalysts. As a new method for catalyst preparation, the synthesis of catalysts in the SCW decreases the sintering problem in Ni-based catalysts compared to the conventional sol-gel method [61]. For instance, Li et al. (2020) [61] compared the stability of various catalysts prepared in SCW and via the sol-gel method in SCWG of glycerol. The investigated catalysts included Ni-based catalysts with supports of $\mathrm{Al}_{2} \mathrm{O}_{3}$ and $\mathrm{Mg}$-promoted $\mathrm{Al}_{2} \mathrm{O}_{3}$, zirconium oxides as $\mathrm{ZrO}_{2}$, and Ce-promoted $\mathrm{ZrO}_{2}$, carbon-based materials as activated carbon, and carbon nanotube. The catalysts prepared in SCW had higher stability during the SCWG operation and during the regeneration stage. Similarly, in situ catalyst preparation in a SCWG process overcame the sintering issue as well as provided excellent stability of crystalline structure and morphology and the good anti-coking ability [62]. Bimetallic catalysts were also investigated to address the deactivation issue by enhancing the stability of catalysts and reducing char formation. For instance, $\mathrm{Ni} / \mathrm{TiO}_{2}, \mathrm{Ni} / \mathrm{ZrO}_{2}$, and $\mathrm{Ni} / \mathrm{Ta}_{2} \mathrm{O}_{5}$ catalysts were stated as "hydrothermally stable" or "hydrothermally stabilized" beds while $\mathrm{Ni}-\mathrm{Zr}$ and $\mathrm{Ni}-\mathrm{Ta}$ showed better persistence, activity, and anti-coking ability with increasing residence time [167]. In addition, nickel-cobalt catalyst with magnesium-aluminum support reduced fouling by decreasing char formation in SCWG as well as having a longer lifespan [168]. As a similar approach, adding a trace amount of transition metal improves the catalyst activity and stability, e.g., as experimented at $21 \mathrm{MPa}$ and $350{ }^{\circ} \mathrm{C}$ by adding $1-5 \%$ ruthenium to a stabilized nickel catalyst [67]. Another approach is to optimize the dispersion of the catalyst on the support. In a comparative study on ruthenium catalysts on various supports, it was shown that the dispersion of catalyst improves the activity and stability: $\mathrm{Ru} / \mathrm{C}$ with enhanced dispersion was very active without significant activity loss after a 50-h operation at $30 \mathrm{MPa}$ and $450{ }^{\circ} \mathrm{C}[169]$.

\subsection{Product quality and further synthesis/ upgrading}

From the industrial application viewpoint, it is also important to evaluate the product quality and to consider further upgrading. The carbon-neutrality would be enabled by producing biofuels with identical or close properties to those of fossil-based fuels. The main properties of HTL oil include heating value and $\mathrm{H} / \mathrm{C}$ and $\mathrm{O} / \mathrm{C}$ atomic ratios from the energy and chemistry viewpoint. As the desired composition, high $\mathrm{H} / \mathrm{C}$ implies low aromatic content, and low O/C implies low oxidation extent [41]. Furthermore, low sulfur and nitrogen contents are desired from the environmental viewpoint. In addition, other relevant properties include acidity and viscosity from the compatibility viewpoint. The syngas properties are evaluated based on the usage because 
of various options of usage. In the case of synthetic natural gas production, the methane content of syngas is the main product parameter while the hydrogen content becomes the main property in the case of pure hydrogen production [143].

The syngas produced in SCWG processes can require downstream processing depending on the usage. The production of synthetic natural gas requires a methanation reactor due to relatively high hydrogen concentration and low methane concentration in the syngas [143]. Similarly, hydrogen production requires the reforming of hydrocarbons in the syngas. Both downstream processes utilize heterogeneous catalysts sensitive against impurities (e.g., tar and sulfur in the syngas). The removal of those impurities is also necessary prior to the gas upgrading. Nevertheless, downstream upgrading might be avoided through a two-stage separation after the SCWG reactor or also including scrubber, depending on the final usage: separating as $\mathrm{CO}_{2}$-rich gas and $\mathrm{H}_{2}$-rich gas (hydrogen and other combustibles) [95, 101]. The $\mathrm{CO}_{2}$-free combustible gas can be used to produce $\mathrm{CHP}$. In addition, CHP and hydrogen can be obtained simultaneously by separating hydrogen (via pressure swing adsorption or chemical looping $[170,171]$ ) and burning the off-gas.

The HTL process provides higher product quality than pyrolysis and slightly less quality than conventional crude oil, in terms of the desired energy and environmental aspects. The oxygen content of HTL oil usually varies around $10-20 \%$ while that of pyrolysis oil is $35-40 \%$ [172]. Meanwhile, crude oil has an oxygen content of 3-5\% or even closer to none. Furthermore, the HTL process provides biooil closer to the conventional crude oil in terms of atomic ratios as shown in Fig. 7. As the main differences between HTL and pyrolysis processes, the biomass decomposition in HTL conditions results in heavier compounds, and the light oxygenated organics are separated in the aqueous phase while those compounds remain in the pyrolysis oil. The separation of light oxygenated compounds, e.g., carboxylic acids, results in more stable bio-oil than pyrolysis in terms of acidity and viscosity. On the other hand, it is required to upgrade the HTL oil for reaching the transportation fuel standards, e.g., gasoline and diesel, and for the removal of sulfur and nitrogen. The gasoline and diesel are also shown in Fig. 7 illustrating the atomic ratios, having very little oxygen and more hydrogen.

Upgrading HTL oil can be conducted through several process options including the addition of polar solvents, emulsification, hydro-cracking/catalytic cracking, hydrotreating/hydrodeoxygenation, supercritical fluids (SCFs), and zeolite cracking [178]. Comparing these technologies, it was concluded that the hydrotreating process provides more favorable upgrading [178]. Polar solvent addition and emulsification are short-term physical treatments while reaching the desired atomic ratios require chemical treatment as well. Moreover, esterification has no significant impact on

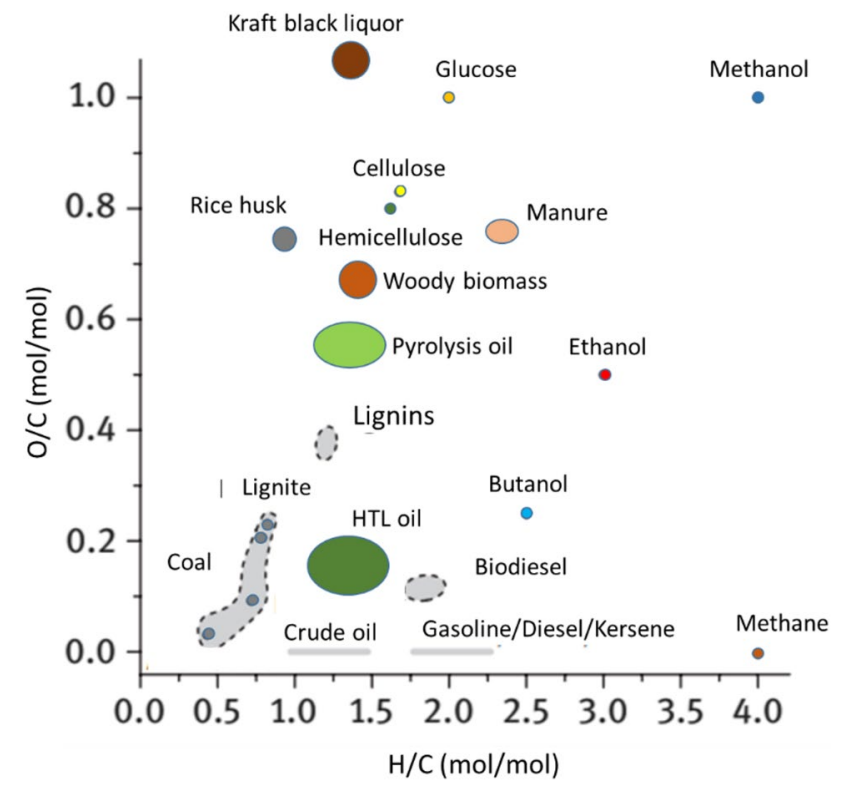

Fig. 7 The atomic ratios of various biomass feedstocks, bio-oils, and petroleum products [173-177]

denitrogenation. Nevertheless, catalytic cracking is another upgrading process with promising improvements in quality [179]. A review on the catalysts stated Ce/HZSM-5, Co/ $\mathrm{Mo} / \mathrm{Al}_{2} \mathrm{O}_{3}$, and $\mathrm{Ni} / \mathrm{SiO}_{2}-\mathrm{Al}_{2} \mathrm{O}_{3}$ to have the highest activities for denitrogenation, deoxygenation, and desulfurization, respectively [180]. However, applying a highly active and stable catalyst for this process with a long lifetime is still a challenge. Moreover, HTL oils from various feedstocks can have different upgrading challenges [181-183]. For instance, Castello et al. (2019) [181] investigated upgrading of three HTL oils originated from miscanthus, microalga Spirulina, and primary sewage sludge with $\mathrm{NiMo} / \mathrm{Al}_{2} \mathrm{O}_{3}$ catalyst. Complete deoxygenation was achieved in the HTL oil from sewage sludge and microalgae as well as reaching remarkable deoxygenation in the HTL oil of the lignocellulosic feedstock [181]. The sewage sludge biocrude content was dominated by straight-chain hydrocarbons in the diesel range while the microalgae biocrude had also branched kinds of paraffin as jet-fuel hydrocarbons [181]. On the other hand, the bio-crude from miscanthus resulted in more aromatics in the gasoline range. Moreover, nitrogen removal still introduces a challenge despite the remarkable removal of heteroatoms [181].

\subsection{Techno-economic feasibility versus process conditions and configurations}

The major costs in SCWG and HTL processes are resulted from the energy demand to reach reaction temperature, the reactor cost, and the heat exchanger costs $[95,97,98,100]$. 
Similarly, major exergy destruction occurs in the reactor and heat exchangers [83]. Therefore, the economic performances of SCWG and HTL processes can be improved through the optimization of process conditions associated with these costs versus revenues from the products. The process conditions introducing major impact include the biomass concentration at the reactor inlet, residence time in the reactor, the reactor material, and reaction temperature. The economic performances of SCWG and HTL are influenced by the whole set of process conditions due to inter-dependent impacts of the conditions on the equipment costs, operation costs, and product yields. Therefore, from the techno-economic viewpoint, Özdenkci et al. (2020) [39] proposed to report the product yields based on kilogram of non-inert inlet to the reactor (water being non-inert as well while ash being the only inert), rather than kilogram of dry or dry-ash-free, together with the main influencing conditions. The non-inert basis provides more accurate information on the yields regarding the reactor inlet concentration influencing the energy demand and equipment size. The residence time and reactor material directly influence the reactor cost. Temperature is also important to note in terms of the applicability of heat integration. In other words, the proposed reporting provides more accurate comparisons for preliminary selections of the promising sets of conditions. Table 5 shows some SCWG results reported as proposed. It can be observed that improving the yields on the kilogram of dry basis can differ from improving that on the kilogram of non-inert basis. Improving the economic performance requires high concentrations at the reactor inlet, high temperature, moderate residence time, and reactor material selection depending on the yields and the material costs. Thermal efficiency can be optimized through heat integration and energy recovery $[83,86]$. In addition, the operation costs due to energy needs can also be reduced through non-conventional heat sources such as solar energy [86]. Moreover, the product yields are required to be verified also in a pilot scale to investigate the impact of the surface-areato-volume ratio of the reactor. The industrial vessel reactors would provide a much less surface area-to-volume ratio compared to the lab-scale tubular reactors.

The techno-economic performances of SCWG and HTL processes are limited by operational issues determining the applicable ranges of process conditions. As a major constraint on the economic performance, the reactor inlet concentration is restricted by the pumpability limits as described in Sect. 3.4. The pumpability limits decrease with pressure, thus introducing a major constraint for SCWG. Consequently, the concentrations of more than $20 \%$ are currently disabled by the pumpability limits in SCWG processes. In addition, the maximum limit can be slightly less depending on the feedstock, e.g., lignocellulosic biomass. Nevertheless, the HTL conditions have higher pumpability limits depending on the pressure. As a process safety restriction, the material constraints at high temperature and pressure affect the equipment and pipeline costs through thickness of process units and suitable material selection. For instance, temperatures higher
Table 5 The results from SCWG of Kraft black liquor (RT: residence time)

\begin{tabular}{|c|c|c|c|c|c|c|c|}
\hline Reactor feed & $\mathrm{P}(\mathrm{MPa})$ & $\mathrm{T}\left({ }^{\circ} \mathrm{C}\right)$ & Reactor material & $\mathrm{RT}(\mathrm{s})$ & $\begin{array}{l}\text { Hydrogen } \\
\text { yield } \\
\text { (mol } \mathrm{H}_{2} / \mathrm{kg} \\
\text { non-inert) } \\
\text { Energy } \\
\text { yield } \\
\text { (kj/kg non- } \\
\text { inert) }\end{array}$ & $\begin{array}{l}\text { Hydrogen yield } \\
\text { (mol/kg organics) } \\
\text { Energy yield } \\
\text { (kj/kg organics) }\end{array}$ & Reference \\
\hline $\begin{array}{l}\text { KBL } \\
4.25 \mathrm{wt} \%\end{array}$ & 25 & 750 & Inconel 625 & 300 & $\begin{array}{l}0.646 \\
458\end{array}$ & $\begin{array}{l}24.92 \\
17,644\end{array}$ & [39] \\
\hline $\begin{array}{l}\text { KBL } \\
4.25 \mathrm{wt} \%\end{array}$ & 25 & 750 & Inconel 625 & 133 & $\begin{array}{l}0.440 \\
315\end{array}$ & $\begin{array}{l}16.93 \\
12,162\end{array}$ & [39] \\
\hline $\begin{array}{l}\text { KBL } \\
4.25 \mathrm{wt} \%\end{array}$ & 25 & 750 & Stainless steel & 133 & $\begin{array}{l}0.370 \\
310\end{array}$ & $\begin{array}{l}14.27 \\
11,963\end{array}$ & [39] \\
\hline $\begin{array}{l}\text { KBL } \\
12.3 \mathrm{wt} \%\end{array}$ & 25 & 700 & Inconel 625 & 77 & $\begin{array}{l}1.238 \\
912\end{array}$ & $\begin{array}{l}14.43 \\
10,627\end{array}$ & {$[40]$} \\
\hline $\begin{array}{l}\text { KBL } \\
12.3 \mathrm{wt} \%\end{array}$ & 25 & 700 & Stainless steel & 77 & $\begin{array}{l}1.232 \\
793\end{array}$ & $\begin{array}{l}14.36 \\
9240\end{array}$ & {$[40]$} \\
\hline $\begin{array}{l}\text { KBL } \\
12.3 \mathrm{wt} \%\end{array}$ & 25 & 600 & Inconel 625 & 91 & $\begin{array}{l}1.478 \\
750\end{array}$ & $\begin{array}{l}17.22 \\
8736\end{array}$ & {$[40]$} \\
\hline $\begin{array}{l}\text { KBL } \\
0.81 \text { wt } \%\end{array}$ & 23.3 & 700 & Inconel 625 & 25 & $\begin{array}{l}0.162 \\
75\end{array}$ & $\begin{array}{l}33.62 \\
15,521\end{array}$ & {$[184]$} \\
\hline $\begin{array}{l}\text { KBL } \\
1.62 \mathrm{wt} \%\end{array}$ & 23.4 & 700 & Inconel 625 & 25 & $\begin{array}{l}0.195 \\
81\end{array}$ & $\begin{array}{l}20.10 \\
16,786\end{array}$ & {$[184]$} \\
\hline
\end{tabular}


than $650{ }^{\circ} \mathrm{C}$ requires Inconel or modified stainless steel reactors for ensuring thermal stability. Moreover, the diameter-to-thickness ratio of process units and pipelines is to be determined based on the operating pressure and tensile strength of the materials. As another major constraint resulting from reactor thickness, it is unfeasible to conduct indirect heating to the reactor. Consequently, the reactor inlet should be heated to the reaction temperature prior to the reactor. This introduces another heat exchanger operating with a high-pressure stream. Moreover, heating the feed stream to SCWG temperatures causes solid precipitation in the heat exchanger and pipelines. This results in process configurations in which the biomass feed and recycling SCW are introduced to the reactor as separate inlet flows as shown in Fig. 8. The reactor outlet shown in Fig. 8 is configured in the same way as the Verena pilot plant to enable solid separation [101, 143]. The biomass feedstock and recycling SCW are mixed at the beginning of the reactor. However, the SCW inlet is to be heated to higher temperature than the reaction temperature to ensure the reaction mixture temperature at the desired value, e.g., through heat exchange with the flue gas (shown as "FLUEGASH" in Fig. 8).

The selection of conversion technology depends extensively on the biomass feedstock and the desired products. SCWG and HTL have different advantages and disadvantages while both processes are suitable for high-moisture biomass without consuming energy for drying. Figure 9 summarizes the pros and cons of these processes. The SCWG product is in the gas phase that can be directly used as a biofuel or to produce other biochemicals. HTL is conducted at lower temperatures than SCWG, so there is no requirement for special reactor and piping materials mentioned in the supercritical conditions. On the other hand, corrosion in HTL is more severe than SCWG. HTL process results in the production of solid, aqueous, and gaseous byproducts. The aqueous phase and solid by-product contain most of the nutrients of biomass feedstock [185]. Moreover, a significant portion of the carbon in feedstock remains in the aqueous phase in HTL processes, i.e., remarkable loss in
Fig. 8 The process configuration of SCWG with the reactor having two inlets and a riser tube for the gas outlet: brown streams representing the biomass feedstock, blue streams representing the aqueous phase, gray streams representing syngas, and green streams representing gas products after separation

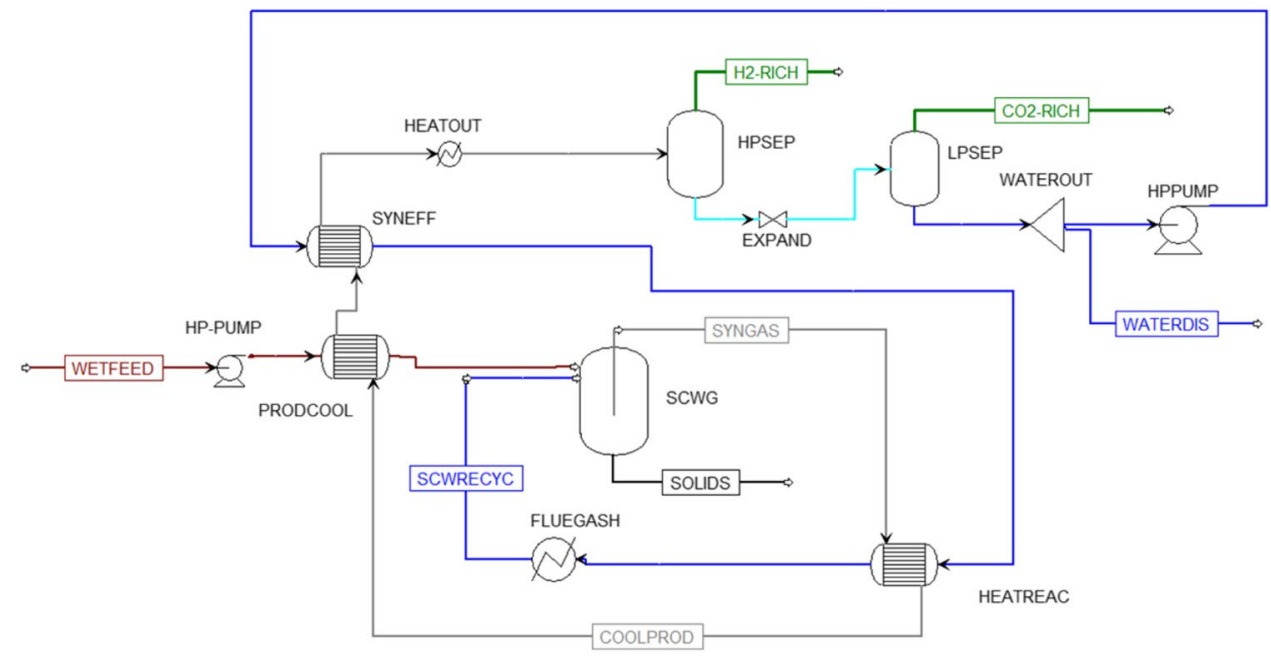

Fig. 9 SCWG and HTL pros and cons

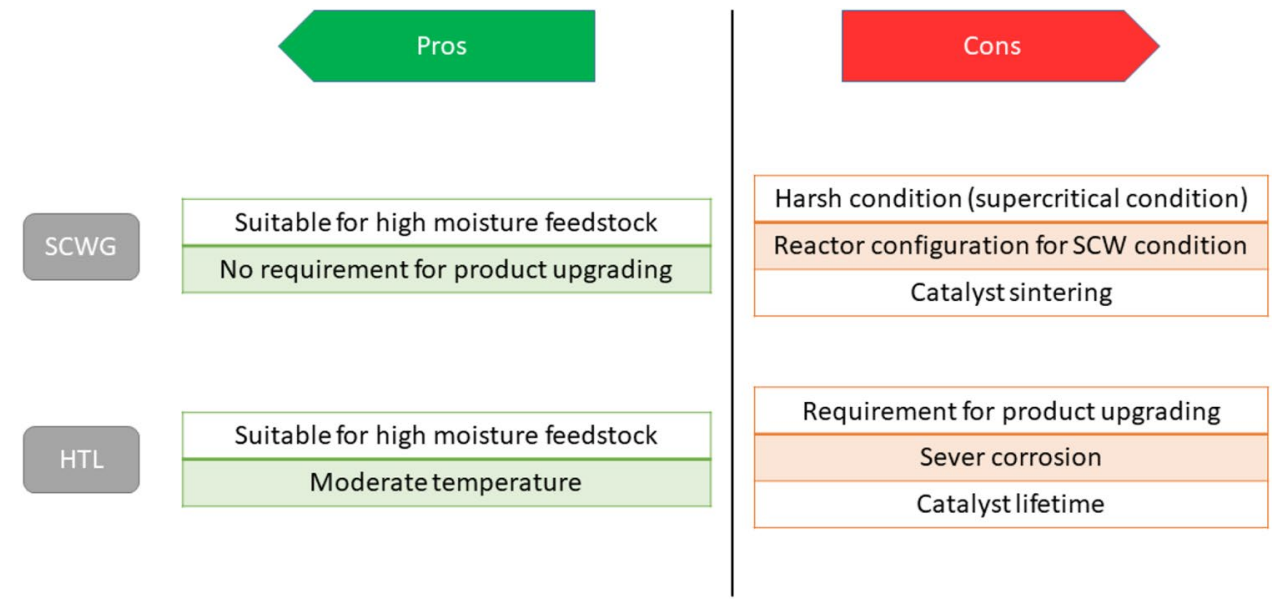


energy content of the feedstock and environmental issue in discharging this phase [186]. Therefore, processing the solid and aqueous phases is important in this process in order to improve the energy efficiency of HTL [187].

SCWG and HTL processes can be integrated with various ways to achieve flexibility regarding product demand and to improve efficiency. The SCWG and HTL reactors can operate in parallel to produce syngas and bio-oil simultaneously. The proportion of inlets to SCWG and HTL can be adjusted in accordance with the demand on bio-oil and syngas, hydrogen, or CHP. Alternatively, the aqueous phase of HTL can be processed in SCWG to recover more energy. In the case of integrated HTL and upgrading, SCWG of the aqueous phase provides hydrogen needed in bio-oil upgrading [188].

Biomass feedstock can introduce a major cost in SCWG and HTL processes, besides other operational costs [86]. For instance, the feedstock cost was around half or more of the operational costs in SCWG of soybean straw and HTL of wood [97, 100]. Similarly, SCWG of black liquor can result in feedstock cost close to half of the operational costs, despite being integrated into a pulp mill [95]. On the other hand, the low-value wastes or residues have also low bulk density, thus increasing the transportation costs to the plants and greenhouse gas emissions [189]. The feedstock transportation was investigated as sub-problem optimization of biomass supply chains [190, 191]. The two-echelon delivery scheme was stated as functional for biomass transportation and the reduction of greenhouse gas emissions: transportation of feedstocks from farmlands to collection stations and from collection stations to the processing plants. Furthermore, the whole supply chain involves transportation of feedstocks to the conversion plants, biomass conversion at these plants, and transportation of products to the demand sites. Sustainable biorefinery concepts require the optimization of the whole chain, e.g., the balance between the transportation costs and chemical conversion costs. The supply chain network design refers to optimizing the locations and capacities of production plants with respect to sustainability measures (e.g., economic and/or environmental indicators), on the constraints of the locations and amounts of feedstocks and amounts of desired products [192-194].

\section{Future aspects of SCWG and HTL operations}

The future target of biorefineries is stated to achieve sustainable production of fuels, energy, and chemicals from biomass sources. The sustainability of biorefineries is determined with several features including fossil-independent productions and supply chains, minimum environmental impacts and carbon neutrality, no compromise with food and animal feed sectors, and the ability to adapt to the variations in biomass availability and market demand. In fact, the biomass conversion processes play a crucial role to meet these features. To enable sustainable replacement of fossils, the conversion processes are desired to involve multi-feed-multiproduct operations and to process a wide spectrum of feedstocks as well as the techno-economic feasibility. In other words, effective biomass conversion processes are required to achieve a sustainable and fossil-independent industry. Figure 10 shows the links among the biomass conversion processes, sustainable supply chain, and socio-economic impacts. From the socio-economic viewpoint, processing
Fig. 10 The inter-relations among biomass conversion processes, sustainable biorefinery, and socio-economic impacts

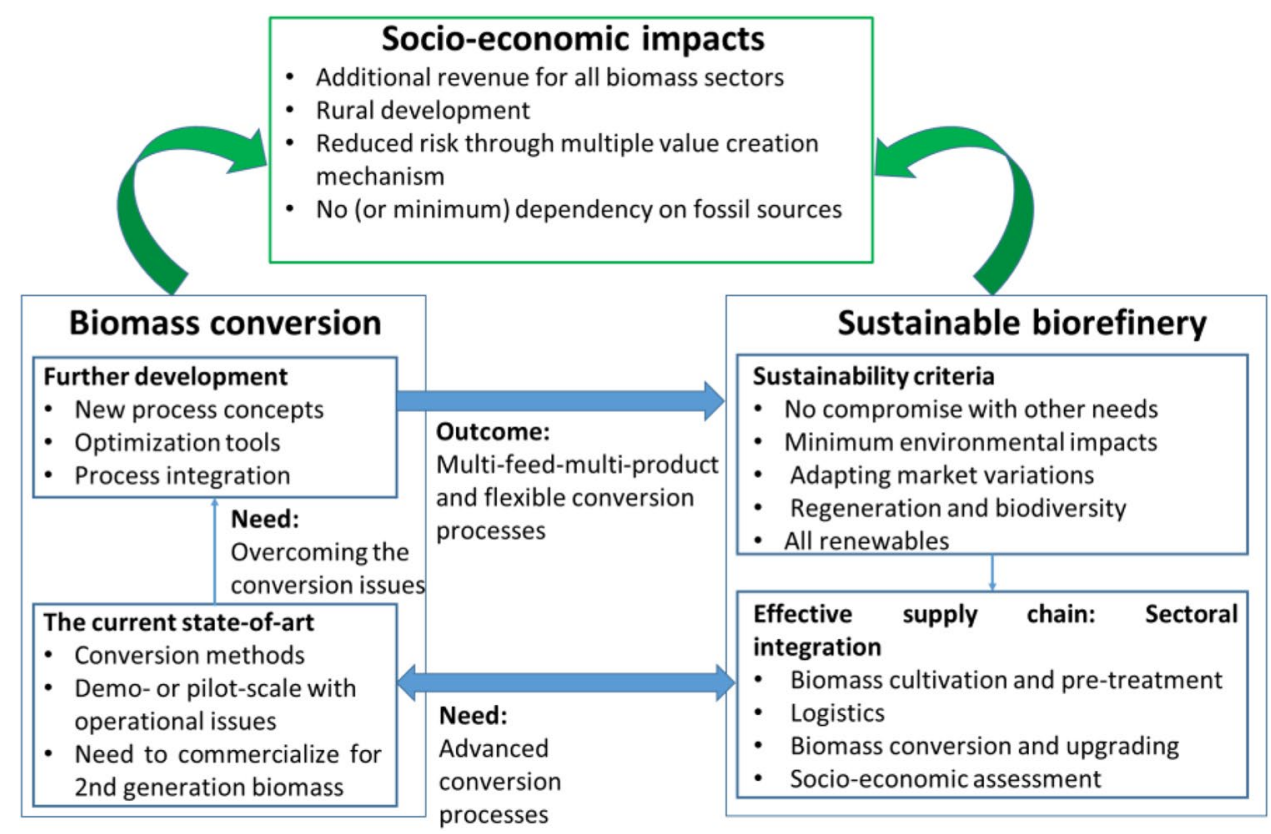


the wastes and side streams of various sectors, effective biomass conversion processes can increase the economic and environmental performances of those sectors simultaneously. On the other hand, the conversion processes have operational issues affecting techno-economic performances. Therefore, it would be a very critical milestone to address the operational issues of promising conversion processes.

The hydrothermal processes provide effective conversion routes of biomass feedstocks with respect to sustainability features as well as being suitable to the high-moisture nature of biomass. Among those processes, SCWG and HTL produce syngas and crude bio-oil as the vital platform substances for the production of CHP, biofuels, and chemicals. Therefore, syngas and bio-oil have inevitable and increasing demand. In addition, SCWG and HTL processes produce these substances of higher quality than the thermal process alternatives. Furthermore, these processes can also convert various biomass feedstocks including agricultural wastes, forest residues, sewage sludge, manure, and algae as well as waste streams or by-products of other production plants (e.g., black liquor in pulp mills and olive mill wastewater). Consequently, it is desirable to improve the techno-economic feasibility of these processes for industrial applications, to address high costs compared to fossil-based productions. However, the commercialization of SCWG and HTL processes is hindered by operational issues introducing constraints on the applicable process conditions, blocking the operation or/and affecting the process configurations. Further research and novel concepts are required to address the operational issues of SCWG and HTL processes besides the currently investigated solutions.

The main phenomena behind most of the operational issues are char formation and the impacts of inorganic salts: causing variations in reactor pressure and plugging in SCWG, corrosion in both SCWG and HTL processes, catalyst deactivation, and affecting product quality. This requires a special reactor configuration enabling solid separation simultaneously with the hydrothermal conversion. The reactor concept of the Verena pilot plant is designed to separate the solids from the bottom. This concept can further be modified considering the techno-economic aspects: catalytic impact of reactor materials, surface area-volume ratio, and the prices of reactor materials. Figure 11 shows a potential reactor concept for enabling solid separation while having a catalytic impact as well. The outer reactor wall can be stainless steel because of its cheaper price and insignificant surface-area-to-volume ratio. The riser tubes can be multiple and coil-shaped made of Inconel material to provide more surface area for the catalytic material. Both the outer and inner surfaces of the riser tubes can function to catalyze the reactors in this concept. Moreover, SCWG reactors should have two inlets for the biomass feedstock at subcritical temperature and SCW to avoid solid precipitation in

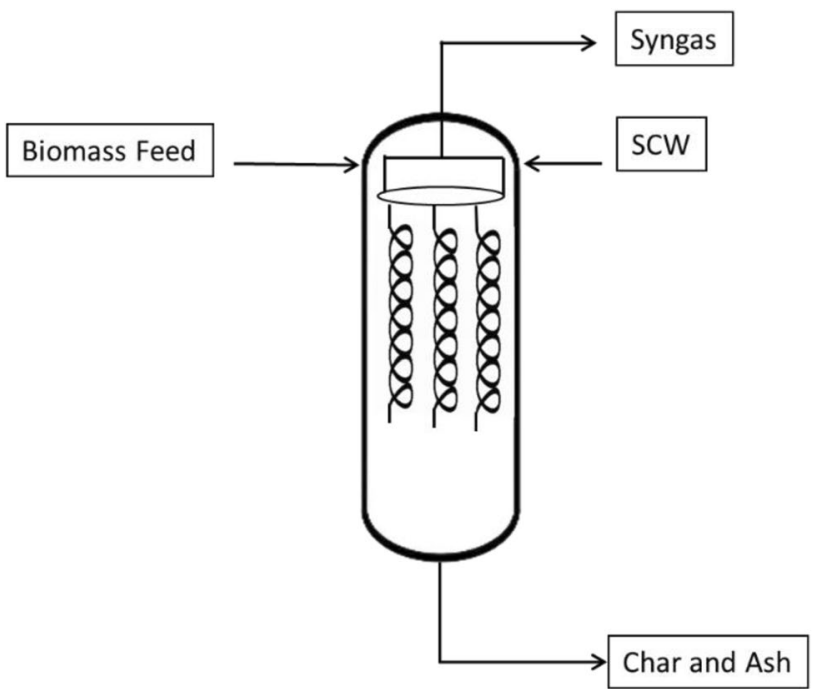

Fig. 11 The reactor concept with multiple, coil-shaped riser tubes

the pipelines and heat exchangers while a single inlet can be sufficient for HTL processes.

Besides the reactor configuration, the process concept can also be enhanced to reduce the char formation and to improve the economic performance of the hydrothermal conversion. For instance, Özdenkçi et al. (2017) [42] proposed partial wet oxidation (PWO) prior to SCWG and HTL reactors. Figure 12 shows the block diagram of the process concept. PWO is an exothermic process at $170-240{ }^{\circ} \mathrm{C}$, thus providing self-heating the feedstock up to this temperature range. Moreover, oxidizing the sulfur content in PWO can provide sulfur-free bio-oil or syngas. The reduction of oxidized sulfur does not occur to a significant extent at temperatures lower than $900{ }^{\circ} \mathrm{C}$ [195]. Consequently, the oxidized sulfur can occur in the salts, i.e., either precipitating in SCWG or dissolved in the aqueous phase in HTL. Furthermore, PWO can reduce char formation in SCWG and HTL reactors by breaking down the large molecules in advance. The light and oxygenated molecules are gasified to a higher extent than the long-chain organics and aromatics [196]. Consequently, char formation can be reduced by introducing the biomass into SCWG or HTL reactor after partial decomposition via PWO. In addition, in the case of lignocellulosic feedstocks, some part of PWO downstream can be used for recovering lignin as another product as applied in pulp mills. Lignin precipitates in black liquor when reducing $\mathrm{pH}$ to 9-10 [197] while PWO enhances the filtering of lignin and enables sulfur-free product [198].

As future aspects, the investigations on SCWG and HTL processes can be directed towards new concepts and solutions to address the operational issues and to extend the application range of process conditions. As a major part of investment costs, the reactor costs can be reduced 
Fig. 12 The block diagram of a process concept involving PWO prior to HTL and SCWG (LR: lignin recovery)

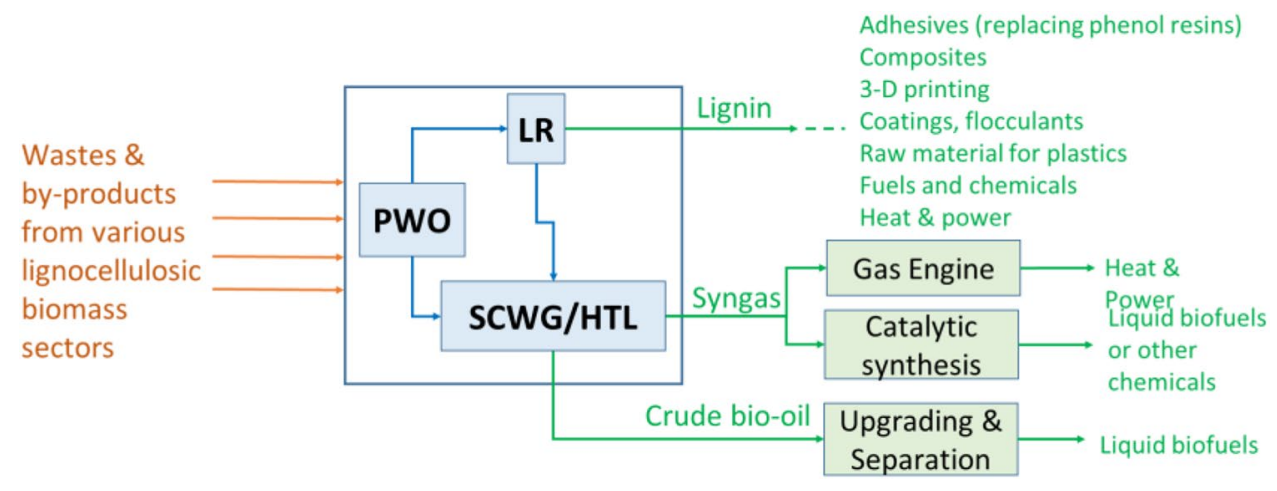

by improving the tensile strength and thermal stability of the materials, thus enabling a higher diameter-to-thickness ratio. This might increase the range of economically feasible residence times for optimizing the process conditions. Meanwhile, the solutions against catalyst deactivation and corrosion would make the product yields of lab-scale studies applicable in industrial processes. As a major operational issue, solid deposition can be addressed by special reactor configurations, partial decomposition of biomass prior to the SCWG or HTL reactor, and recovering the major source of char formation in biomass (i.e., lignin) as another product. From the process development viewpoint, the future scope can involve the proof of concept in Fig. 12 through the experiments of PWO followed by SCWG or HTL for various feedstocks, to validate sulfur-free products and reduce char formation while enhancing the gas and bio-oil yields. Afterward, the whole process is to be optimized with respect to conditions in PWO and SCWG or HTL. In addition, the reactor configuration Fig. 11 can also be implemented in a pilot-scale process to verify the solid separation simultaneously with catalytic conversion of biomass.

\section{Conclusion}

Biomass represents an abundant and renewable source for replacing fossil sources and enabling carbon-neutrality. Sustainability aspects emphasize the usage of 2nd-generation biomass in chemical, fuel, and energy production. However, conversion of 2 nd-generation of biomass requires advanced processes and currently results in higher production costs than conventional fossil-based processes. Therefore, it is crucial to select suitable conversion technologies with respect to the biomass feedstock and to enhance the technoeconomic performance of these processes.

The hydrothermal processes present promising conversion routes because of the high moisture content of biomass feedstocks: high energy efficiencies, product yields, and quality compared to thermal processes. The SCWG and HTL processes produce syngas and bio-oil as crucial platform chemicals from waste streams and residues of biomass sectors. Commercial implementation of these processes can improve the biomass supply chains from environmental and economic viewpoints. However, these processes undergo operational issues reducing the economic performance and/ or endangering process safety. In other words, the operational issues are obstacles to the process development of SCWG and HTL technologies. Therefore, a holistic investigation is required to determine the obstacles, root causes, and potential solutions comprehensively.

This study reviews the operational issues of SCWG and HTL processes together with the phenomena causing the issues and solutions addressing these issues. The main issue is process safety regarding thermal and mechanical stress on the reactor due to high pressure and temperature. Addressing this issue requires proper selection of reactor material and diameter-to-thickness ratio considering the operating pressure and the tensile strength of materials at the operating temperature. Regarding the reactor and pipeline material, corrosion is another issue regarding long-term operation. Corrosion results from the presence of alkali salts, char formation, and corrosive inorganics (sulfur, chloride, or nitrate). This issue is currently addressed through corrosion-resistant material selection and optimum conditions minimizing char formation as well as adjusting the feedstock via mixing with another non-corrosive feedstock or pre-neutralization. Catalyst deactivation is another long-term issue reducing the product yields. This can occur due to chemical degradation (chemisorption of intermediate organics on active sites), sintering of heterogeneous catalysts at high temperatures, or fouling (due to deposition of unreactive species on catalyst surface). The catalyst deactivation can be reduced through different catalyst preparation methods, and enhanced dispersion, adding a trace amount of transition metals to alkali metal catalysts and bimetallic catalysts. In addition, the biomass concentration into a reactor inlet is restricted by pumpability limits to high pressure. This issue introduces a constraint to the applicable concentration range when investigating the optimum 
conditions. Moreover, solid deposition is the main obstacle increasing the occurrence risks of other issues as well. Solid deposition results from char formation (in SCWG and HTL) and precipitation of inorganic salts (in SCWG). This issue causes mechanical stress on the reactor through variation of pressure, under-deposit corrosion, dealloying in case of sulfide, and catalyst deactivation through fouling. Addressing this issue requires special reactor configurations enabling solid separation simultaneously with the reactions while providing a surface area of catalytic wall in an economically feasible way, besides optimum conditions minimizing the char formation.

The future aspects can include new concepts of integrating SCWG and HTL, enhanced reactor configurations. As a new concept, PWO of the feedstock prior to the SCWG or HTL reactor can reduce the char formation and provide sulfur-free products as well as slightly improve the energy efficiency. As an enhanced reactor configuration, the reactor can have two outlets: to collect the products through multiple, coil-shaped riser tubes while solids precipitate to the bottom outlet. Addressing the operational issues will also improve the techno-economic performances of SCWG and HTL processes. The further scope can be to investigate these processes involving the new solutions, e.g., experiments of PWO followed by SCWG or HTL with various feedstocks and a new reactor configuration. In other words, the operational issues present the main obstacle also affecting economic feasibility. Therefore, effective solutions can enable the efficient implementation of SCWG and HTL processes, thus improving the biomass supply chains.

The commercialization of SCWG and HTL processes will improve the biomass supply chains as well: the whole chain of transporting the residues/wastes from the fields to conversion plants, the processes converting these feedstocks into intermediates, and/or final products, and transportation of the final product. The techno-economic performances of biorefineries can be evaluated through profitability measures, exergy analysis, and LCA within the whole supply chain. It is essential to optimize the supply chain network, and conversion processes are the heart of these chains.

Acknowledgements We acknowledge the Regional Council of Ostrobothnia for their support in conducting the EU-ERUF project named "Implementation of a hydrothermal carbonization process for the disposal sludge and wet organic streams."

Funding Open access funding provided by Abo Akademi University (ABO). This work received financial support from the University Foundation in Ostrobothnia (Högskolestiftelsen) [28600114K1], EU Commission, and the Aktia Foundation [28600114K3].

\section{Declarations}

Competing interests The authors declare no competing interests.

Open Access This article is licensed under a Creative Commons Attribution 4.0 International License, which permits use, sharing, adaptation, distribution and reproduction in any medium or format, as long as you give appropriate credit to the original author(s) and the source, provide a link to the Creative Commons licence, and indicate if changes were made. The images or other third party material in this article are included in the article's Creative Commons licence, unless indicated otherwise in a credit line to the material. If material is not included in the article's Creative Commons licence and your intended use is not permitted by statutory regulation or exceeds the permitted use, you will need to obtain permission directly from the copyright holder. To view a copy of this licence, visit http://creativecommons.org/licenses/by/4.0/.

\section{References}

1. Exxonmobil (2019) Outlook for energy: a perspective to 2040

2. Butera G, Fendt S, Jensen SH et al (2020) Flexible methanol production units coupling solid oxide cells and thermochemical biomass conversion via different gasification technologies. Energy 208:118432. https://doi.org/10.1016/j.energy.2020.118432

3. Liu L, Wu L (2021) Forecasting the renewable energy consumption of the European countries by an adjacent non-homogeneous grey model. Appl Math Model 89:1932-1948. https://doi.org/10. 1016/j.apm.2020.08.080

4. Sikkema R, Proskurina S, Banja M, Vakkilainen E (2021) How can solid biomass contribute to the EU's renewable energy targets in 2020, 2030 and what are the GHG drivers and safeguards in energy- and forestry sectors? Renewable Energy 165:758-772. https://doi.org/10.1016/j.renene.2020.11.047

5. Energy Policies of IEA Countries: Finland 2018 Review. In: IEA Webstore. https://webstore.iea.org/energy-policies-of-iea-count ries-finland-2018-review. Accessed 2 Jan 2021

6. Ma J, Wei H, Liu Y et al (2020) Application of Co3O4-based materials in electrocatalytic hydrogen evolution reaction: a review. Int J Hydrogen Energy 45:21205-21220. https://doi.org/ 10.1016/j.ijhydene.2020.05.280

7. Meng J, Mäkelä MR, de Vries RP (2020) Molecular engineering to improve lignocellulosic biomass based applications using filamentous fungi. In: Advances in Applied Microbiology. Academic Press

8. Mailaram S, Kumar P, Kunamalla A et al (2021) 3 - Biomass, biorefinery, and biofuels. In: Dutta S, Mustansar Hussain C (eds) Sustainable Fuel Technologies Handbook. Academic Press, pp $51-87$

9. Ganguly P, Sarkhel R, Das P (2021) 2 - The second- and thirdgeneration biofuel technologies: comparative perspectives. In: Dutta S, Mustansar Hussain C (eds) Sustainable Fuel Technologies Handbook. Academic Press, pp 29-50

10. Luque R, Herrero-Davila L, Campelo JM et al (2008) Biofuels: a technological perspective. Energy Environ Sci 1:542-564. https://doi.org/10.1039/B807094F

11. Cherubini F (2010) The biorefinery concept: using biomass instead of oil for producing energy and chemicals. Energy Convers Manage 51:1412-1421. https://doi.org/10.1016/j.enconman. 2010.01.015

12. Elliott DC (2004) Biomass, chemicals from C. J. Cleveland. Elsevier Inc, Oxford

13. Aggarwal S, Hakovirta M (2021) Supercritical carbon dioxide drying of municipal sewage sludge - novel waste-to-energy 
valorization pathway. J Environ Manage 285:112148. https:// doi.org/10.1016/j.jenvman.2021.112148

14. Byun J, Kwon O, Park H, Han J (2021) Food waste valorization to green energy vehicles: sustainability assessment. Energy Environ Sci. https://doi.org/10.1039/D1EE00850A

15. Yaashikaa PR, Kumar PS, Varjani S, Saravanan A (2020) A critical review on the biochar production techniques, characterization, stability and applications for circular bioeconomy. Biotechnology Reports 28:e0570. https://doi.org/10.1016/j.btre.2020. e00570

16. Shahbaz M, Al-Ansari T, Aslam M et al (2020) A state of the art review on biomass processing and conversion technologies to produce hydrogen and its recovery via membrane separation. Int J Hydrogen Energy 45:15166-15195. https://doi.org/10.1016/j. ijhydene.2020.04.009

17. Das P, V.p. C, Mathimani T, Pugazhendhi A (2021) Recent advances in thermochemical methods for the conversion of algal biomass to energy. Science of The Total Environment 766:144608. https://doi.org/10.1016/j.scitotenv.2020.144608

18. Ishola MM, Brandberg T, Taherzadeh MJ (2015) Simultaneous glucose and xylose utilization for improved ethanol production from lignocellulosic biomass through SSFF with encapsulated yeast. Biomass Bioenerg 77:192-199. https://doi.org/10.1016/j. biombioe.2015.03.021

19. Zheng Y, Pan Z, Zhang R (2009) Overview of biomass pretreatment for cellulosic ethanol production. Int J Agric Biol Eng 2:51-68. https://doi.org/10.25165/ijabe.v2i3.168

20. Ma W, Ma C, Liu X et al (2021) Nox formation in fixed-bed biomass combustion: Chemistry and modeling. Fuel 290:119694. https://doi.org/10.1016/j.fuel.2020.119694

21. Sharma P, Gupta B, Pandey M, et al (2020) Downdraft biomass gasification: a review on concepts, designs analysis, modelling and recent advances. Mater Today: Proc. https://doi.org/10. 1016/j.matpr.2020.08.789

22. Habibollahzade A, Ahmadi P, Rosen MA (2021) Biomass gasification using various gasification agents: optimum feedstock selection, detailed numerical analyses and tri-objective grey wolf optimization. J Clean Prod 284:124718. https://doi.org/10.1016/j. jclepro.2020.124718

23. Galvagno A, Prestipino M, Maisano S et al (2019) Integration into a citrus juice factory of air-steam gasification and CHP system: energy sustainability assessment. Energy Convers Manage 193:74-85. https://doi.org/10.1016/j.enconman.2019.04.067

24. Galvagno A, Prestipino M, Chiodo V et al (2017) Energy performance of CHP system integrated with citrus peel air-steam gasification: a comparative study. Energy Procedia 126:485-492. https://doi.org/10.1016/j.egypro.2017.08.233

25. Grammelis P, Margaritis N, Kourkoumpas D-S (2018) 4.27 Pyrolysis energy conversion systems. In: Dincer I (ed) Comprehensive Energy Systems. Elsevier, Oxford, pp 1065-1106

26. Balat M, Balat M, Kirtay E, Balat H (2009) Main routes for the thermo-conversion of biomass into fuels and chemicals. Part 1: Pyrolysis systems. Energy Convers Manage 50:3147-3157. https://doi.org/10.1016/j.enconman.2009.08.014

27. Kılıç M, Pütün AE, Uzun BB, Pütün E (2014) Converting of oil shale and biomass into liquid hydrocarbons via pyrolysis. Energy Convers Manage 78:461-467. https://doi.org/10.1016/j. enconman.2013.11.002

28. Bridgwater AV (2012) Review of fast pyrolysis of biomass and product upgrading. Biomass Bioenerg 38:68-94. https://doi.org/ 10.1016/j.biombioe.2011.01.048

29. Zafar MW, Sinha A, Ahmed Z et al (2021) Effects of biomass energy consumption on environmental quality: the role of education and technology in Asia-Pacific Economic Cooperation countries. Renew Sustain Energy Rev 142:110868. https://doi. org/10.1016/j.rser.2021.110868
30. Briones-Hidrovo A, Copa J, Tarelho LAC, et al (2021) Environmental and energy performance of residual forest biomass for electricity generation: gasification vs. combustion. J Clean Prod 289:125680. https://doi.org/10.1016/j.jclepro.2020.125680

31. Bareschino P, Mancusi E, Urciuolo M et al (2020) Life cycle assessment and feasibility analysis of a combined chemical looping combustion and power-to-methane system for $\mathrm{CO} 2$ capture and utilization. Renew Sustain Energy Rev 130:109962. https:// doi.org/10.1016/j.rser.2020.109962

32. Cormos C-C (2020) Techno-economic implications of flexible operation for super-critical power plants equipped with calcium looping cycle as a thermo-chemical energy storage system. Fuel 280:118293. https://doi.org/10.1016/j.fuel.2020.118293

33. Balat M, Balat M, Kirtay E, Balat H (2009) Main routes for the thermo-conversion of biomass into fuels and chemicals. Part 2: gasification systems. Energy Convers Manage 50:3158-3168. https://doi.org/10.1016/j.enconman.2009.08.013

34. Saidur R, BoroumandJazi G, Mekhilef S, Mohammed HA (2012) A review on exergy analysis of biomass based fuels. Renew Sustain Energy Rev 16:1217-1222. https://doi.org/10. 1016/j.rser.2011.07.076

35. Lepage T, Kammoun M, Schmetz Q, Richel A (2021) Biomassto-hydrogen: a review of main routes production, processes evaluation and techno-economical assessment. Biomass Bioenerg 144:105920. https://doi.org/10.1016/j.biombioe.2020. 105920

36. Gagliano A, Nocera F, Bruno M (2018) 2 - simulation models of biomass thermochemical conversion processes, gasification and pyrolysis, for the prediction of the energetic potential. In: Yahyaoui I (ed) Advances in Renewable Energies and Power Technologies. Elsevier, pp 39-85

37. Yoshida Y, Dowaki K, Matsumura Y et al (2003) Comprehensive comparison of efficiency and $\mathrm{CO} 2$ emissions between biomass energy conversion technologies-position of supercritical water gasification in biomass technologies. Biomass Bioenerg 25:257-272. https://doi.org/10.1016/S0961-9534(03)00016-3

38. Naqvi M, Yan J, Dahlquist E (2010) Black liquor gasification integrated in pulp and paper mills: a critical review. Biores Technol 101:8001-8015. https://doi.org/10.1016/j.biortech. 2010.05.013

39. Özdenkçi K, Prestipino M, Björklund-Sänkiaho M et al (2020) Alternative energy valorization routes of black liquor by stepwise supercritical water gasification: effect of process parameters on hydrogen yield and energy efficiency. Renew Sustain Energy Rev 134:110146. https://doi.org/10.1016/j.rser.2020. 110146

40. De Blasio C, Lucca G, Özdenkci K et al (2016) A study on supercritical water gasification of black liquor conducted in stainless steel and nickel-chromium-molybdenum reactors. J Chem Technol Biotechnol 91:2664-2678. https://doi.org/10.1002/jctb.4871

41. Tekin K, Karagöz S, Bektaş S (2014) A review of hydrothermal biomass processing. Renew Sustain Energy Rev 40:673-687. https://doi.org/10.1016/j.rser.2014.07.216

42. Özdenkçi K, De Blasio C, Muddassar HR et al (2017) A novel biorefinery integration concept for lignocellulosic biomass. Energy Convers Manage 149:974-987. https://doi.org/10.1016/j. enconman.2017.04.034

43. Hu Y, Gong M, Xing X et al (2020) Supercritical water gasification of biomass model compounds: a review. Renew Sustain Energy Rev 118:109529. https://doi.org/10.1016/j.rser.2019. 109529

44. Kruse A, Dahmen N (2015) Water - a magic solvent for biomass conversion. J Supercrit Fluids 96:36-45. https://doi.org/ 10.1016/j.supflu.2014.09.038 
45. Rogers GFC, Mayhew YR (1994) Thermodynamic and transport properties of fluids: S. I. Units, 5th edition. Wiley-Blackwell, Oxford

46. Marshall WL, Franck E (1981) Ion product of water substance, 0-1000 C, 1-10,000 Bars. New International Formulation and Its Background. https://doi.org/10.1063/1.555643

47. Guo Y, Wang SZ, Xu DH et al (2010) Review of catalytic supercritical water gasification for hydrogen production from biomass. Renew Sustain Energy Rev 14:334-343. https://doi.org/ 10.1016/j.rser.2009.08.012

48. Kabyemela BM, Adschiri T, Malaluan RM, Arai K (1999) Glucose and fructose decomposition in subcritical and supercritical water: detailed reaction pathway, mechanisms, and kinetics. Ind Eng Chem Res 38:2888-2895. https://doi.org/10.1021/ie9806390

49. Sasaki M, Kabyemela B, Malaluan R et al (1998) Cellulose hydrolysis in subcritical and supercritical water. J Supercrit Fluids 13:261-268. https://doi.org/10.1016/S0896-8446(98)00060-6

50. Fang Z, Sato T, Smith RL et al (2008) Reaction chemistry and phase behavior of lignin in high-temperature and supercritical water. Biores Technol 99:3424-3430. https://doi.org/10.1016/j. biortech.2007.08.008

51. Yanik J, Ebale S, Kruse A et al (2007) Biomass gasification in supercritical water: part 1. Effect of the nature of biomass. Fuel 86:2410-2415. https://doi.org/10.1016/j.fuel.2007.01.025

52. Akhtar J, Amin NAS (2011) A review on process conditions for optimum bio-oil yield in hydrothermal liquefaction of biomass. Renew Sustain Energy Rev 15:1615-1624. https://doi.org/10. 1016/j.rser.2010.11.054

53. Savage PE, Levine RB, Huelsman CM (2010) Chapter 8:hydrothermal processing of biomass. In: Thermochemical Conversion of Biomass to Liquid Fuels and Chemicals. pp 192-221

54. Simsek Kus N (2012) Organic reactions in subcritical and supercritical water. Tetrahedron 68:949-958. https://doi.org/ $10.1016 /$ j.tet.2011.10.070

55. Sricharoenchaikul V (2009) Assessment of black liquor gasification in supercritical water. Biores Technol 100:638-643. https://doi.org/10.1016/j.biortech.2008.07.011

56. Cao C, Guo L, Chen Y et al (2011) Hydrogen production from supercritical water gasification of alkaline wheat straw pulping black liquor in continuous flow system. Int J Hydrogen Energy 36:13528-13535. https://doi.org/10.1016/j.ijhydene.2011.07. 101

57. Yin S, Dolan R, Harris M, Tan Z (2010) Subcritical hydrothermal liquefaction of cattle manure to bio-oil: effects of conversion parameters on bio-oil yield and characterization of bio-oil. Biores Technol 101:3657-3664. https://doi.org/10.1016/j.biortech.2009. 12.058

58. Zhou D, Zhang L, Zhang S et al (2010) Hydrothermal liquefaction of macroalgae Enteromorpha prolifera to bio-oil. Energy Fuels 24:4054-4061. https://doi.org/10.1021/ef100151h

59. Zhang L, Champagne P, (Charles) Xu C, (2011) Bio-crude production from secondary pulp/paper-mill sludge and waste newspaper via co-liquefaction in hot-compressed water. Energy 36:2142-2150. https://doi.org/10.1016/j.energy.2010.05.029

60. Yong TL-K, Matsumura Y (2012) Reaction kinetics of the lignin conversion in supercritical water. https://pubs.acs.org/doi/ full/https://doi.org/10.1021/ie300921d. Accessed 28 Mar 2019

61. Li S, Zhu B, Wang W et al (2020) Efficient and stable supercritical-water-synthesized Ni-based catalysts for supercritical water gasification. J Supercrit Fluids 160:104790. https://doi.org/10. 1016/j.supflu.2020.104790

62. Zhu B, Li S, Wang W, Zhang H (2019) Supercritical water synthesized $\mathrm{Ni} / \mathrm{ZrO} 2$ catalyst for hydrogen production from supercritical water gasification of glycerol. Int J Hydrogen Energy 44:30917-30926. https://doi.org/10.1016/j.ijhydene.2019.10.044
63. Nazari L, Yuan Z, Souzanchi S et al (2015) Hydrothermal liquefaction of woody biomass in hot-compressed water: catalyst screening and comprehensive characterization of bio-crude oils. Fuel 162:74-83. https://doi.org/10.1016/j.fuel.2015.08.055

64. Toor SS, Rosendahl L, Rudolf A (2011) Hydrothermal liquefaction of biomass: a review of subcritical water technologies. Energy 36:2328-2342. https://doi.org/10.1016/j.energy.2011.03. 013

65. Muangrat R, Onwudili JA, Williams PT (2010) Influence of alkali catalysts on the production of hydrogen-rich gas from the hydrothermal gasification of food processing waste. Appl Catal B 100:440-449. https://doi.org/10.1016/j.apcatb.2010.08.019

66. Wang Y, Wang H, Lin $\mathrm{H}$ et al (2013) Effects of solvents and catalysts in liquefaction of pinewood sawdust for the production of bio-oils. Biomass Bioenerg 59:158-167. https://doi.org/10. 1016/j.biombioe.2013.10.022

67. Elliott DC, Hart TR, Neuenschwander GG (2006) Chemical processing in high-pressure aqueous environments. 8. Improved Catalysts for Hydrothermal Gasification. Ind Eng Chem Res 45:3776-3781. https://doi.org/10.1021/ie060031o

68. Luterbacher JS, Fröling M, Vogel F et al (2009) Hydrothermal gasification of waste biomass: process design and life cycle asessment. Environ Sci Technol 43:1578-1583. https://doi.org/ 10.1021/es801532f

69. Castello D, Rolli B, Kruse A, Fiori L (2017) Supercritical water gasification of biomass in a ceramic reactor: long-time batch experiments. Energies 10:1734. https://doi.org/10.3390/en101 11734

70. Tuan Abdullah TA, Croiset E (2014) Evaluation of an Inconel-625 Reactor and its wall effects on ethanol reforming in supercritical water. Ind Eng Chem Res 53:2121-2129. https:// doi.org/10.1021/ie403305d

71. Lee CS, Conradie AV, Lester E (2021) Review of supercritical water gasification with lignocellulosic real biomass as the feedstocks: Process parameters, biomass composition, catalyst development, reactor design and its challenges. Chem Eng J 415:128837. https://doi.org/10.1016/j.cej.2021.128837

72. Mastuli MS, Kamarulzaman N, Kasim MF et al (2017) Catalytic gasification of oil palm frond biomass in supercritical water using $\mathrm{MgO}$ supported $\mathrm{Ni}, \mathrm{Cu}$ and $\mathrm{Zn}$ oxides as catalysts for hydrogen production. Int J Hydrogen Energy 42:11215-11228. https://doi. org/10.1016/j.ijhydene.2017.02.174

73. Yakaboylu O, Harinck J, Smit KG, De Jong W (2015) Supercritical water gasification of biomass: a literature and technology overview. Energies 8:859-894. https://doi.org/10.3390/en802 0859

74. Karayıldırım T, Sınağ A, Kruse A (2008) Char and coke formation as unwanted side reaction of the hydrothermal biomass gasification. Chem Eng Technol 31:1561-1568. https://doi.org/ 10.1002/ceat.200800278

75. Yoshida T, Matsumura Y (2001) Gasification of cellulose, xylan, and lignin mixtures in supercritical water. Ind Eng Chem Res 40:5469-5474. https://doi.org/10.1021/ie0101590

76. Kruse A, Dahmen N (2018) Hydrothermal biomass conversion: Quo vadis? J Supercrit Fluids 134:114-123. https://doi.org/10. 1016/j.supflu.2017.12.035

77. Rodriguez Correa C, Kruse A (2018) Supercritical water gasification of biomass for hydrogen production - review. J Supercrit Fluids 133:573-590. https://doi.org/10.1016/j.supflu.2017.09. 019

78 Yang J (Sophia), He Q, Yang L (2019) A review on hydrothermal co-liquefaction of biomass. Appl Energy 250:926-945. https:// doi.org/10.1016/j.apenergy.2019.05.033

79. Leng L, Zhang W, Peng $\mathrm{H}$ et al (2020) Nitrogen in bio-oil produced from hydrothermal liquefaction of biomass: a review. 
Chem Eng J 401:126030. https://doi.org/10.1016/j.cej.2020. 126030

80. Su H, Kanchanatip E, Wang D et al (2020) Production of H2-rich syngas from gasification of unsorted food waste in supercritical water. Waste Manage 102:520-527. https://doi.org/10.1016/j. wasman.2019.11.018

81. Reddy SN, Nanda S, Dalai AK, Kozinski JA (2014) Supercritical water gasification of biomass for hydrogen production. Int $\mathbf{J}$ Hydrogen Energy 39:6912-6926. https://doi.org/10.1016/j.ijhyd ene.2014.02.125

82. Azadi P, Farnood R (2011) Review of heterogeneous catalysts for sub- and supercritical water gasification of biomass and wastes. Int J Hydrogen Energy 36:9529-9541. https://doi.org/10.1016/j. ijhydene.2011.05.081

83. Chen J, Liang J, Xu Z, E J, (2020) Assessment of supercritical water gasification process for combustible gas production from thermodynamic, environmental and techno-economic perspectives: a review. Energy Convers Manage 226:113497. https://doi. org/10.1016/j.enconman.2020.113497

84. Wei N, Xu D, Hao B et al (2021) Chemical reactions of organic compounds in supercritical water gasification and oxidation. Water Res 190:116634. https://doi.org/10.1016/j.watres.2020. 116634

85. Okolie JA, Nanda S, Dalai AK et al (2020) A review on subcritical and supercritical water gasification of biogenic, polymeric and petroleum wastes to hydrogen-rich synthesis gas. Renew Sustain Energy Rev 119:109546. https://doi.org/10.1016/j.rser. 2019.109546

86. Ibrahim ABA, Akilli H (2019) Supercritical water gasification of wastewater sludge for hydrogen production. Int J Hydrogen Energy 44:10328-10349. https://doi.org/10.1016/j.ijhydene. 2019.02.184

87. Shahabuddin M, Alam MT, Krishna BB et al (2020) A review on the production of renewable aviation fuels from the gasification of biomass and residual wastes. Biores Technol 312:123596. https://doi.org/10.1016/j.biortech.2020.123596

88. Scarsella M, de Caprariis B, Damizia M, De Filippis P (2020) Heterogeneous catalysts for hydrothermal liquefaction of lignocellulosic biomass: a review. Biomass Bioenerg 140:105662. https://doi.org/10.1016/j.biombioe.2020.105662

89. Leng S, Leng L, Chen L et al (2020) The effect of aqueous phase recirculation on hydrothermal liquefaction/carbonization of biomass: a review. Biores Technol 318:124081. https://doi. org/10.1016/j.biortech.2020.124081

90. Matsumura Y, Minowa T (2004) Fundamental design of a continuous biomass gasification process using a supercritical water fluidized bed. Int J Hydrogen Energy 29:701-707. https://doi. org/10.1016/j.ijhydene.2003.09.005

91. Li J, Chen J, Chen S (2018) Supercritical water treatment of heavy metal and arsenic metalloid-bioaccumulating-biomass. Ecotoxicol Environ Saf 157:102-110. https://doi.org/10.1016/j. ecoenv.2018.03.069

92. Zhang H, Gong M, Ding L, Su Y (2020) Energy recovery and phosphorus phase behaviour from catalytic gasification of cyanobacterial biomass in supercritical water. Biomass Bioenerg 134:105477. https://doi.org/10.1016/j.biombioe.2020. 105477

93. Adar E, Ince M, Bilgili MS (2020) Supercritical water gasification of sewage sludge by continuous flow tubular reactor: a pilot scale study. Chem Eng J 391:123499. https://doi.org/10. 1016/j.cej.2019.123499

94. Pinkard BR (2019) Supercritical water gasification: practical design strategies and operational challenges for lab-scale, continuous flow reactors. 32

95. Özdenkçi K, De Blasio C, Sarwar G et al (2019) Techno-economic feasibility of supercritical water gasification of black liquor. Energy 189:116284. https://doi.org/10.1016/j.energy. 2019.116284

96. Magdeldin M, Järvinen M (2020) Supercritical water gasification of Kraft black liquor: process design, analysis, pulp mill integration and economic evaluation. Appl Energy 262:114558. https://doi.org/10.1016/j.apenergy.2020.114558

97. Okolie JA, Nanda S, Dalai AK, Kozinski JA (2021) Technoeconomic evaluation and sensitivity analysis of a conceptual design for supercritical water gasification of soybean straw to produce hydrogen. Biores Technol 331:125005. https://doi.org/ 10.1016/j.biortech.2021.125005

98. Tews IJ, Zhu Y, Drennan C, et al (2014) Biomass direct liquefaction options. TechnoEconomic and Life Cycle Assessment. Pacific Northwest National Lab. (PNNL), Richland, WA (United States)

99. Spath PL, Mann MK, Amos WA (2003) Update of hydrogen from biomass -- determination of the delivered cost of hydrogen. National Renewable Energy Lab., Golden, CO. (US)

100. Zhu Y, Biddy MJ, Jones SB et al (2014) Techno-economic analysis of liquid fuel production from woody biomass via hydrothermal liquefaction (HTL) and upgrading. Appl Energy 129:384-394. https://doi.org/10.1016/j.apenergy.2014.03.053

101. Boukis N, Galla U, Müller H, et al (2007) Biomass gasification in supercritical water. Experimental progress achieved with the verena pilot plant. 4

102. Matsumura Y (2015) Chapter 9 - hydrothermal gasification of biomass. In: Pandey A, Bhaskar T, Stöcker M, Sukumaran RK (eds) Recent advances in thermo-chemical conversion of biomass. Elsevier, Boston, pp 251-267

103. Anastasakis K, Biller P, Madsen RB et al (2018) Continuous hydrothermal liquefaction of biomass in a novel pilot plant with heat recovery and hydraulic oscillation. Energies 11:2695. https://doi.org/10.3390/en11102695

104. Elliott DC, Biller P, Ross AB et al (2015) Hydrothermal liquefaction of biomass: developments from batch to continuous process. Biores Technol 178:147-156. https://doi.org/10.1016/j.biortech. 2014.09.132

105. Oh DH, Race J, Oterkus S, Chang E (2020) A new methodology for the prediction of burst pressure for API 5L X grade flawless pipelines. Ocean Eng 212:107602. https://doi.org/10.1016/j. oceaneng.2020.107602

106. De Blasio C, Salierno G, Magnano A (2021) Implications on feedstock processing and safety issues for semi-batch operations in supercritical water gasification of biomass. Energies 14:2863. https://doi.org/10.3390/en14102863

107. Deterimine Tubing Burst Pressure and Working Pressure I TBL Plastics. https://www.tblplastics.com/how-to-determine-tubingburst-pressure-and-working-pressure/. Accessed 18 Nov 2021

108. Steel M Inconel vs Stainless Steel: Which is Stronger? https:// www.marlinwire.com/blog/inconel-vs-stainless-steel-which-isstronger. Accessed 3 Nov 2021

109. Li Y, Wang S, Xu T et al (2021) Novel designs for the reliability and safety of supercritical water oxidation process for sludge treatment. Process Saf Environ Prot 149:385-398. https://doi. org/10.1016/j.psep.2020.10.049

110. Wang S, Li J, Cao Y et al (2018) Thermal stability and tensile property of $316 \mathrm{~L}$ stainless steel with heterogeneous lamella structure. Vacuum 152:261-264. https://doi.org/10.1016/j.vacuum.2018.03.040

111. Kosmač A (2012) Stainless steels at high temperatures. Euro Inox, Brussels

112. De Blasio C, De Gisi S, Molino A et al (2019) Concerning operational aspects in supercritical water gasification of kraft black liquor. Renew Energy 130:891-901. https://doi.org/10.1016/j. renene.2018.07.004 
113. Waldeck WF, Lynn G, Hill AE (1932) Aqueous solubility of salts at high temperatures. I. SOLUBILITY OF SODIUM CARBONATE FROM 50 TO $348^{\circ} 1$. J Am Chem Soc 54:928-936. https:// doi.org/10.1021/ja01342a012

114. Voisin T, Erriguible A, Ballenghien D et al (2017) Solubility of inorganic salts in sub- and supercritical hydrothermal environment: application to SCWO processes. J Supercrit Fluids 120:18-31. https://doi.org/10.1016/j.supflu.2016.09.020

115. Marshall WL (1975) Water and its solutions at high temperatures and pressures. Chemistry 48:6-12

116. Valyashko VM (2004) Chapter 15 - Phase equilibria of watersalt systems at high temperatures and pressures. In: Palmer DA, Fernández-Prini R, Harvey AH (eds) Aqueous Systems at Elevated Temperatures and Pressures. Academic Press, London, pp 597-641

117. Zhang Y, Wang S, Song W et al (2019) Characteristics of sodium sulfate deposition in hydrogen production from supercritical water gasification: a review. Int J Hydrogen Energy 44:2946729482. https://doi.org/10.1016/j.ijhydene.2019.05.125

118. Hodes M, Marrone PA, Hong GT et al (2004) Salt precipitation and scale control in supercritical water oxidation-part A: fundamentals and research. J Supercrit Fluids 29:265-288. https:// doi.org/10.1016/S0896-8446(03)00093-7

119. Armellini FJ, Tester JW, Hong GT (1994) Precipitation of sodium chloride and sodium sulfate in water from sub- to supercritical conditions: 150 to $550{ }^{\circ} \mathrm{C}, 100$ to 300 bar. J Supercrit Fluids 7:147-158. https://doi.org/10.1016/0896-8446(94)90019-1

120. Schubert M, Regler JW, Vogel F (2010) Continuous salt precipitation and separation from supercritical water. Part 2. Type 2 salts and mixtures of two salts. J Supercrit Fluids 52:113-124. https:// doi.org/10.1016/j.supflu.2009.10.003

121. Schubert M, Regler JW, Vogel F (2010) Continuous salt precipitation and separation from supercritical water. Part 1: type 1 salts. J Supercrit Fluids 52:99-112. https://doi.org/10.1016/j.supflu. 2009.10.002

122. Resende FLP, Fraley SA, Berger MJ, Savage PE (2008) Noncatalytic gasification of lignin in supercritical water. Energy Fuels 22:1328-1334. https://doi.org/10.1021/ef700574k

123. Kruse A, Meier D, Rimbrecht P, Schacht M (2000) Gasification of pyrocatechol in supercritical water in the presence of potassium hydroxide. Ind Eng Chem Res 39:4842-4848. https://doi. org/10.1021/ie0001570

124. Watanabe M, Inomata $H$, Osada $M$ et al (2003) Catalytic effects of $\mathrm{NaOH}$ and $\mathrm{ZrO} 2$ for partial oxidative gasification of n-hexadecane and lignin in supercritical wateriz. Fuel 82:545-552. https://doi.org/10.1016/S0016-2361(02)00320-4

125. Sinağ A, Kruse A, Schwarzkopf V Key Compounds of the hydropyrolysis of glucose in supercritical water in the presence of $\mathrm{K} 2 \mathrm{CO} 3$ I Industrial \& Engineering Chemistry Research. https://pubs.acs.org/doi/abs/https://doi.org/10.1021/ie030079r. Accessed 25 Feb 2021

126. Miyaoka H, Nakajima K, Yamaguchi S, et al Catalysis of lithium chloride and alkali metal borohydrides on hydrogen generation of ammonia and lithium hydride system I The Journal of Physical Chemistry C. https://pubs.acs.org/doi/abs/https://doi.org/10. 1021/acs.jpcc.5b05572. Accessed 25 Feb 2021

127. Xu D, Wang S, Hu X et al (2009) Catalytic gasification of glycine and glycerol in supercritical water. Int J Hydrogen Energy 34:5357-5364. https://doi.org/10.1016/j.ijhydene.2008.08.055

128. Ebadi AG, Hisoriev H, Zarnegar M, Ahmadi H Hydrogen and syngas production by catalytic gasification of algal biomass (Cladophora glomerata L.) using alkali and alkaline-earth metals compounds. https://iahr.tandfonline.com/doi/full/https://doi.org/ 10.1080/09593330.2017.1417495\#.YDfaiWgzaM8. Accessed 25 Feb 2021
129. Vadillo V, Sánchez-Oneto J, Portela JR, Martínez de la Ossa EJ (2013) Problems in supercritical water oxidation process and proposed solutions. Ind Eng Chem Res 52:7617-7629. https:// doi.org/10.1021/ie400156c

130. Xu D, Huang C, Wang S et al (2015) Salt deposition problems in supercritical water oxidation. Chem Eng J 279:1010-1022. https://doi.org/10.1016/j.cej.2015.05.040

131. Vogel F (2017) Hydrothermal conversion of biomass. In: Meyers RA (ed) Encyclopedia of Sustainability Science and Technology. Springer, New York, New York, pp 1-46

132. Marrone PA, Hong GT (2009) Corrosion control methods in supercritical water oxidation and gasification processes. 21

133. Kruse A, Forchheim D, Gloede M et al (2010) Brines in supercritical biomass gasification: 1 . Salt extraction by salts and the influence on glucose conversion. J Supercrit Fluids 53:64-71. https://doi.org/10.1016/j.supflu.2010.01.001

134. Wang S, Gong Y, Ma H, et al (2014) Countercurrent tank type supercritical water reactor with a sacrificial lining

135. Barner HE, Huang CY, Johnson T et al (1992) Supercritical water oxidation: an emerging technology. J Hazard Mater 31:1-17. https://doi.org/10.1016/0304-3894(92)87035-E

136. Huang C-Y (1992) Apparatus and method for supercritical water oxidation

137. Calzavara Y, Joussot-Dubien C, Turc H-A et al (2004) A new reactor concept for hydrothermal oxidation. J Supercrit Fluids 31:195-206. https://doi.org/10.1016/j.supflu.2003.11.001

138. Cocero MJ, Martínez JL (2004) Cool wall reactor for supercritical water oxidation: modelling and operation results. J Supercrit Fluids 31:41-55. https://doi.org/10.1016/j.supflu.2003.09.023

139. Wellig B, Lieball $\mathrm{K}$, von Rohr R, Ph, (2005) Operating characteristics of a transpiring-wall SCWO reactor with a hydrothermal flame as internal heat source. J Supercrit Fluids 34:35-50. https:// doi.org/10.1016/j.supflu.2004.07.003

140. Xu D, Wang S, Huang C et al (2014) Transpiring wall reactor in supercritical water oxidation. Chem Eng Res Des 92:2626-2639. https://doi.org/10.1016/j.cherd.2014.02.028

141. Veriansyah B, Kim J, Kim J-D, Lee Y-W (2008) Hydrogen production by gasification of isooctane using supercritical water. Int J Green Energy 5:322-333. https://doi.org/10.1080/1543507080 2229084

142. Susanti RF, Veriansyah B, Kim J-D et al (2010) Continuous supercritical water gasification of isooctane: a promising reactor design. Int J Hydrogen Energy 35:1957-1970. https://doi.org/ 10.1016/j.ijhydene.2009.12.157

143. Boukis N, Stoll IK (2021) Gasification of biomass in supercritical water, challenges for the process design-lessons learned from the operation experience of the first dedicated pilot plant. Processes 9:455. https://doi.org/10.3390/pr9030455

144. Jin H, Lu Y, Liao B et al (2010) Hydrogen production by coal gasification in supercritical water with a fluidized bed reactor. Int J Hydrogen Energy 35:7151-7160. https://doi.org/10.1016/j. ijhydene.2010.01.099

145. Lee A, Lewis D, Kalaitzidis T, Ashman P (2016) Technical issues in the large-scale hydrothermal liquefaction of microalgal biomass to biocrude. Curr Opin Biotechnol 38:85-89. https://doi. org/10.1016/j.copbio.2016.01.004

146. Guo B, Walter V, Hornung U, Dahmen N (2019) Hydrothermal liquefaction of Chlorella vulgaris and Nannochloropsis gaditana in a continuous stirred tank reactor and hydrotreating of biocrude by nickel catalysts. Fuel Process Technol 191:168-180. https:// doi.org/10.1016/j.fuproc.2019.04.003

147. Kosinkova J, Ramirez JA, Nguyen J et al (2015) Hydrothermal liquefaction of bagasse using ethanol and black liquor as solvents. Biofuels, Bioprod Biorefin 9:630-638. https://doi.org/10. 1002/bbb. 1578 
148. Cao L, Zhang C, Hao S et al (2016) Effect of glycerol as cosolvent on yields of bio-oil from rice straw through hydrothermal liquefaction. Biores Technol 220:471-478. https://doi.org/ 10.1016/j.biortech.2016.08.110

149. Wang X, Xie X, Sun J, Liao W (2019) Effects of liquefaction parameters of cellulose in supercritical solvents of methanol, ethanol and acetone on products yield and compositions. Biores Technol 275:123-129. https://doi.org/10.1016/j.biortech.2018. 12.047

150. Feng S, Wei R, Leitch M, Xu CC (2018) Comparative study on lignocellulose liquefaction in water, ethanol, and water/ethanol mixture: roles of ethanol and water. Energy 155:234-241. https:// doi.org/10.1016/j.energy.2018.05.023

151. Marrone PA, Hong GT (2009) Corrosion control methods in supercritical water oxidation and gasification processes. J Supercrit Fluids 51:83-103. https://doi.org/10.1016/j.supflu.2009.08. 001

152. Kritzer P (2004) Corrosion in high-temperature and supercritical water and aqueous solutions: a review. J Supercrit Fluids 29:1-29. https://doi.org/10.1016/S0896-8446(03)00031-7

153. Hirose T, Shiba K, Enoeda M, Akiba M (2007) Corrosion and stress corrosion cracking of ferritic/martensitic steel in super critical pressurized water. J Nucl Mater 5

154. Brady MP, Keiser JR, Leonard DN et al (2014) Corrosion considerations for thermochemical biomass liquefaction process systems in biofuel production. JOM 66:2583-2592. https://doi. org/10.1007/s11837-014-1201-y

155. Chang K-H (2012) Corrosion behavior of Alloy 625 in supercritical water environments. Progr Nucl Energy 12

156. Ferreira-Pinto L Experimental basic factors in the production of $\mathrm{H} 2$ via supercritical water gasification. in te $\mathrm{r}$ a t $\mathrm{i}$ o $\mathrm{n}$ a $\mathrm{lj}$ o u rn al of hy drogenenergy 19

157. Vadillo V, García-Jarana MB, Sánchez-Oneto J et al (2012) New feed system for water-insoluble organic and/or highly concentrated wastewaters in the supercritical water oxidation process. J Supercrit Fluids 72:263-269. https://doi.org/10.1016/j.supflu. 2012.09.011

158. Cocero MJ (2018) Supercritical water processes: future prospects. J Supercrit Fluids 134:124-132. https://doi.org/10.1016/j. supflu.2017.11.018

159. Xu X, Matsumura Y, Stenberg J, Antal MJ (1996) Carbon-catalyzed gasification of organic feedstocks in supercritical water ${ }^{\dagger}$. Ind Eng Chem Res 35:2522-2530. https://doi.org/10.1021/ie950 $672 b$

160. Berglin E, Enderlin C, Schmidt A (2012) Review and assessment of commercial vendors/options for feeding and pumping biomass slurries for hydrothermal liquefaction. Pacific Northwest National Lab. (PNNL), Richland, WA (United States)

161. Kruse A (2009) Hydrothermal biomass gasification. J Supercrit Fluids 47:391-399. https://doi.org/10.1016/j.supflu.2008.10.009

162. Elliott DC, Hart TR, Schmidt AJ et al (2013) Process development for hydrothermal liquefaction of algae feedstocks in a continuous-flow reactor. Algal Res 2:445-454. https://doi.org/ 10.1016/j.algal.2013.08.005

163. Seiple TE, Skaggs RL, Fillmore L, Coleman AM (2020) Municipal wastewater sludge as a renewable, cost-effective feedstock for transportation biofuels using hydrothermal liquefaction. J Environ Manage 270:110852. https://doi.org/10.1016/j.jenvm an.2020.110852

164. Bartholomew CH (2001) Mechanisms of catalyst deactivation. Appl Catal A 212:17-60. https://doi.org/10.1016/S0926860X(00)00843-7

165. Yoshida T, Oshima Y, Matsumura Y (2004) Gasification of biomass model compounds and real biomass in supercritical water. Biomass Bioenerg 26:71-78. https://doi.org/10.1016/S09619534(03)00063-1
166. Cao L, Zhang C, Chen $\mathrm{H}$ et al (2017) Hydrothermal liquefaction of agricultural and forestry wastes: state-of-the-art review and future prospects. Biores Technol 245:1184-1193. https://doi.org/ 10.1016/j.biortech.2017.08.196

167. Li S, Savage PE, Guo L (2019) Stability and activity maintenance of sol-gel Ni-MxOy $(\mathrm{M}=\mathrm{Ti}, \mathrm{Zr}, \mathrm{Ta})$ catalysts during continuous gasification of glycerol in supercritical water. J Supercrit Fluids 148:137-147. https://doi.org/10.1016/j.supflu.2019.02.028

168. Kang K, Azargohar R, Dalai AK, Wang H (2017) Hydrogen generation via supercritical water gasification of lignin using $\mathrm{Ni}-\mathrm{Co} /$ Mg-Al catalysts. Int J Energy Res 41:1835-1846. https://doi.org/ 10.1002/er.3739

169. Peng G, Ludwig C, Vogel F (2016) Ruthenium dispersion: a key parameter for the stability of supported ruthenium catalysts during catalytic supercritical water gasification. ChemCatChem 8:139-141. https://doi.org/10.1002/cctc.201500995

170. Darmawan A, Ajiwibowo MW, Biddinika MK et al (2019) Black liquor-based hydrogen and power co-production: combination of supercritical water gasification and syngas chemical looping. Appl Energy 252:113446. https://doi.org/10.1016/j.apenergy. 2019.113446

171. Ajiwibowo MW, Darmawan A, Aziz M (2019) Co-production of hydrogen and power from black liquor via supercritical water gasification, chemical looping and power generation. Energy Procedia 158:2299-2304. https://doi.org/10.1016/j. egypro.2019.01.259

172. Lehto J, Oasmaa A, Solantausta Y, et al Fuel oil quality and combustion of fast pyrolysis bio-oils. VTT Technical research Center of Finland

173. Vendra Singh S, Chaturvedi S, Dhyani VC, Kasivelu G (2020) Pyrolysis temperature influences the characteristics of rice straw and husk biochar and sorption/desorption behaviour of their biourea composite. Biores Technol 314:123674. https:// doi.org/10.1016/j.biortech.2020.123674

174. Wu K, Zhang X, Yuan Q, Liu R (2020) Investigation of physico-chemical properties of hydrochar and composition of bio-oil from the hydrothermal treatment of dairy manure: effect of type and usage volume of extractant. Waste Manage 116:157-165. https://doi.org/10.1016/j.wasman.2020.08.004

175. Rinaldi R, Schüth F (2009) Design of solid catalysts for the conversion of biomass. Energy Environ Sci 2:610-626. https:// doi.org/10.1039/B902668A

176. Ramirez JA, Brown RJ, Rainey TJ (2015) A review of hydrothermal liquefaction bio-crude properties and prospects for upgrading to transportation fuels. Energies 8:6765-6794. https://doi.org/10.3390/en8076765

177. Santos RB, Gomide JL, Hart PW (2015) Kraft pulping of reduced metal content eucalyptus wood: process impacts. BioResources 10:6538-6547

178. Arvindnarayan S, Sivagnana Prabhu KK, Shobana S et al (2017) Upgrading of micro algal derived bio-fuels in thermochemical liquefaction path and its perspectives: a review. Int Biodeterior Biodegrad 119:260-272. https://doi.org/10.1016/j. ibiod.2016.08.011

179. Saber M, Nakhshiniev B, Yoshikawa K (2016) A review of production and upgrading of algal bio-oil. Renew Sustain Energy Rev 58:918-930. https://doi.org/10.1016/j.rser.2015.12.342

180. Xu D, Lin G, Guo S et al (2018) Catalytic hydrothermal liquefaction of algae and upgrading of biocrude: a critical review. Renew Sustain Energy Rev 97:103-118. https://doi.org/10. 1016/j.rser.2018.08.042

181. Castello D, Haider MS, Rosendahl LA (2019) Catalytic upgrading of hydrothermal liquefaction biocrudes: different challenges for different feedstocks. Renew Energy 141:420 430. https://doi.org/10.1016/j.renene.2019.04.003 
182. Duan P, Savage PE (2011) Upgrading of crude algal bio-oil in supercritical water. Biores Technol 102:1899-1906. https://doi. org/10.1016/j.biortech.2010.08.013

183. Yang C, Li R, Cui C et al (2016) Catalytic hydroprocessing of microalgae-derived biofuels: a review. Green Chem 18:36843699. https://doi.org/10.1039/C6GC01239F

184. Casademont P, Sánchez-Oneto J, Scandelai APJ et al (2020) Hydrogen production by supercritical water gasification of black liquor: use of high temperatures and short residence times in a continuous reactor. The J Supercrit Fluids 159:104772. https://doi.org/10.1016/j.supflu.2020.104772

185. López Barreiro D, Bauer M, Hornung U et al (2015) Cultivation of microalgae with recovered nutrients after hydrothermal liquefaction. Algal Res 9:99-106. https://doi.org/10.1016/j. algal.2015.03.007

186. Duan P-G, Yang S-K, Xu Y-P et al (2018) Integration of hydrothermal liquefaction and supercritical water gasification for improvement of energy recovery from algal biomass. Energy 155:734-745. https://doi.org/10.1016/j.energy.2018.05.044

187. Davidson SD, Lopez-Ruiz JA, Zhu Y et al (2019) Strategies to valorize the hydrothermal liquefaction-derived aqueous phase into fuels and chemicals. ACS Sustainable Chem Eng 7:19889-19901. https://doi.org/10.1021/acssuschemeng.9b053 08

188. Ong BHY, Walmsley TG, Atkins MJ, Walmsley MRW (2020) A Kraft mill-integrated hydrothermal liquefaction process for liquid fuel co-production. Processes 8:1216. https://doi.org/10. 3390/pr8101216

189. Sun F, Aguayo MM, Ramachandran R, Sarin SC (2018) Biomass feedstock supply chain design - a taxonomic review and a decomposition-based methodology. Int J Prod Res 56:56265659. https://doi.org/10.1080/00207543.2018.1475766

190. Li S, Wang Z, Wang X et al (2019) Integrated optimization model of a biomass feedstock delivery problem with carbon emissions constraints and split loads. Comput Ind Eng 137:106013. https:// doi.org/10.1016/j.cie.2019.106013
191. Aguayo MM, Sarin SC, Cundiff JS (2019) A branch-and-price approach for a biomass feedstock logistics supply chain design problem. IISE Trans 51:1348-1364. https://doi.org/10.1080/ 24725854.2019.1589656

192. Sharma B, Ingalls RG, Jones CL, Khanchi A (2013) Biomass supply chain design and analysis: basis, overview, modeling, challenges, and future. Renew Sustain Energy Rev 24:608-627. https://doi.org/10.1016/j.rser.2013.03.049

193. Kim J, Realff MJ, Lee JH et al (2011) Design of biomass processing network for biofuel production using an MILP model. Biomass Bioenerg 35:853-871. https://doi.org/10.1016/j.biomb ioe.2010.11.008

194. You F, Wang B (2011) Life cycle optimization of biomass-toliquid supply chains with distributed-centralized processing networks. Ind Eng Chem Res 50:10102-10127. https://doi.org/10. 1021/ie200850t

195. Wrobel CL (2000) Modeling total reduced sulfur and sulfur dioxide emissions from a kraft recovery boiler using an artificial neural network and Investigating volatile organic compounds in an urban intermountain valley using a TD/GC/MS methodology and intrinsic tracer molecules. University of Montana

196. Chakinala AG, Kumar S, Kruse A et al (2013) Supercritical water gasification of organic acids and alcohols: the effect of chain length. J Supercrit Fluids 74:8-21. https://doi.org/10.1016/j.supflu.2012.11.013

197. Tomani P (2010) The LignoBoost process. Cellul Chem Technol 44:53-58

198. Kouisni L, Gagné A, Maki K et al (2016) LignoForce system for the recovery of lignin from black liquor: feedstock options, odor profile, and product characterization. ACS Sustainable Chem Eng 4:5152-5159. https://doi.org/10.1021/acssuschemeng.6b009 07

Publisher's note Springer Nature remains neutral with regard to jurisdictional claims in published maps and institutional affiliations. 